\title{
Performance of McRAS-AC in the GEOS-5 AGCM: aerosol-cloud-microphysics, precipitation, cloud radiative effects, and circulation
}

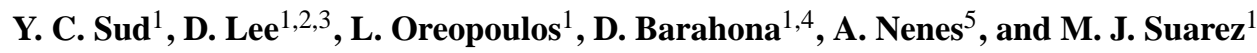 \\ ${ }^{1}$ NASA Goddard Space Flight Center, Greenbelt, MD, USA \\ ${ }^{2}$ Universities Space Research Association, Columbia, MD, USA \\ ${ }^{3}$ Seoul National University, Seoul, South Korea \\ ${ }^{4}$ I.M. Systems Group Inc., Rockville, Maryland, USA \\ ${ }^{5}$ School of Atmospheric and Earth Science, Georgia Tech. Atlanta, Georgia, USA \\ Correspondence to: Y. C. Sud (yogesh.c.sud@nasa.gov)
}

Received: 11 May 2012 - Published in Geosci. Model Dev. Discuss.: 8 June 2012

Revised: 12 December 2012 - Accepted: 14 December 2012 - Published: 17 January 2013

\begin{abstract}
A revised version of the Microphysics of clouds with Relaxed Arakawa-Schubert and Aerosol-Cloud interaction scheme (McRAS-AC) including, among others, a new ice nucleation parameterization, is implemented in the GEOS-5 AGCM. Various fields from a 10-yr-long integration of the AGCM with McRAS-AC are compared with their counterparts from an integration of the baseline GEOS-5 AGCM, as well as satellite observations. Generally McRASAC simulations have smaller biases in cloud fields and cloud radiative effects over most of the regions of the Earth than the baseline GEOS-5 AGCM. Two systematic biases are identified in the McRAS-AC runs: one is underestimation of cloud particle numbers around $40^{\circ} \mathrm{S}-60^{\circ} \mathrm{S}$, and one is overestimate of cloud water path during the Northern Hemisphere summer over the Gulf Stream and North Pacific. Sensitivity tests show that these biases potentially originate from biases in the aerosol input. The first bias is largely eliminated in a test run using $50 \%$ smaller radius of sea-salt aerosol particles, while the second bias is substantially reduced when interactive aerosol chemistry is turned on. The main weakness of McRAS-AC is the dearth of low-level marine stratus clouds, a probable outcome of lack of explicit dry-convection in the cloud scheme. Nevertheless, McRAS-AC largely simulates realistic clouds and their optical properties that can be improved further with better aerosol input. An assessment using the COSP simulator in a 1-yr integration provides additional perspectives for understanding cloud optical property
\end{abstract}

differences between the baseline and McRAS-AC simulations and biases against satellite data. Overall, McRAS-AC physically couples aerosols, the microphysics and macrophysics of clouds, and their radiative effects and thereby has better potential to be a valuable tool for climate modeling research.

\section{Introduction}

Traditionally, meteorologists have focused on severe weather and precipitation forecasts and much less attention was paid to cloud water. There are two reasons for this. First, in-cloud water constitutes less than $5 \%$ of the precipitation generated in a typical weather episode; second, weather forecasts are useful only up to a week or less, which is an insufficient period for cloudiness and its radiative effects to exert much influence on the synoptic weather systems. Consequently, ad hoc ways to assess cloud radiative forcing were deemed adequate. However, once the emphasis of forecasting turned to climate change, radiative forcings and everything that affects them such as greenhouse gases, clouds, influence of aerosols on clouds and many key aspects of cloud radiative effects (CREs) became quite important. Among them, the parameterization of cloud-aerosol interaction (Andreae and Rosenfeld, 2008) is in early stages of development, but the progress is rapid (e.g., Quaas et al., 2004; Roelofs et al., 2006; Sud 
and Lee, 2007; Morrison and Gettelman 2008; Stevens and Feingold, 2009; Liu et al., 2011). Toward this goal, we have recently revised and updated the aerosol-cloud interaction (AC) module of McRAS (Microphysics of clouds with Relaxed Arakawa-Schubert) cloud scheme. This manuscript presents the implementation of the revised McRAS-AC in the GEOS-5 atmospheric general circulation model (AGCM) and evaluates its CRE-related interactions against the available satellite observations.

The pioneering works of Gibbs $(1876,1878)$ and Köhler (1936) laid the foundation of physics behind cloud droplet formation, but its use in global climate models had to wait till the aerosol datasets and computer power to perform aerosol-cloud-radiation interactions became feasible. Combined with the cloud-scale dynamics and associated supersaturation, and condensate deposition on existing cloud droplets (e.g., Nenes et al., 2001) or cloud ice particles, many physically based aerosol activation parameterizations for GCMs have emerged (e.g., Abdul-Razzak and Ghan, 2000, 2002; Nenes and Seinfeld, 2003; Liu and Penner, 2005; Barahona and Nenes, 2009a, b; Ghan et al., 2011). Higher aerosol particle number densities lead to a corresponding increase in the number density of activated cloud particles (CP) (Twomey, 1977; Seinfeld and Pandis, 1996); thereby, they suppress autoconversion and accretion that form precipitating hydrometeors (e.g., Albrecht, 1989; Seifert and Beheng, 2001, 2006). Several recent studies have shown the impact of aerosols on (i) weather and climate prediction (Lohmann, 2006; Kim et al., 2006; Krishnamurti et al., 2009; Sud et al., 2009; Wilcox et al., 2009; Lau et al., 2009), with a few simulations studies having been performed with an earlier version of McRASAC that used Liu and Penner (2005) ice nucleation parameterization; (ii) the diurnal and seasonal cycles of precipitation (Kim et al., 2010); (iii) the weekly cycle of precipitation over central North America (Bell et al., 2009b); (iv) the increase in the incidence of tornados (e.g., Rosenfeld and Bell, 2011) and lightning (Bell et al., 2009a); (v) the vertical stability of the atmosphere leading to the so-called "elevated heat pump" hypothesis affecting the Indian monsoons (Lau and Kim, 2007); and (vi) the freezing of in-cloud liquid drops leading to release of latent heat of freezing with its effects on precipitation (Rosenfeld, 2000, 2006). The debate on how and/or to what extent aerosols influence different clouds in a way that fosters or suppresses precipitation from different cloud types continues (e.g., Gunturu, 2010; Li et al., 2011; Lance et al., 2011; Koren et al., 2012). Whereas some of the pioneering works cited above need further validation, nevertheless they bring out the importance of aerosols for many weather- and climate-related issues. As stated before, a direct consequence of increasing cloud particle number concentrations (CPNCs) by aerosols is the corresponding reduction in cloud particle sizes. In turn, it slows the autoconversion and accretion of cloud drops to form precipitation size hydrometeors, and when it happens in a convective tower, it gives liquid cloud particles and embryonic raindrops the time to ascend with the convective updrafts and later glaciate at subfreezing temperatures; consequent release of latent heat of freezing in turn augments the cloud buoyancy and enables the clouds to ascend higher. How this manifests in convective clouds depends upon how much further the convective towers ascend and how much additional liquid precipitation is carried aloft. These in turn depend on the local atmospheric sounding and need physics-based parameterizations.

Numerical models equipped with appropriate aerosolcloud-precipitation microphysics parameterizations can simulate all of the above processes, if the ambient aerosol fields are realistically prescribed and/or simulated interactively. However, many GCMs still obtain clouds invoking a number of simplifying and/or ad hoc assumptions (Bacmeister et al., 2006; Randall, 2010) that often ignore the aerosol effects on clouds. Despite major efforts of many present-day climate modelers to include fully prognostic parameterizations of the direct and indirect aerosol effects that are compared with other leading models for the performance evaluation (Bellouin et al., 2011), the present-day understanding of the climatic impact of aerosols has some well-accepted weaklinks (IPCC, 2007); a few parameterization algorithm(s) and aerosol data-related complexities and uncertainties confound these efforts. For example, aerosol input, namely aerosol size distribution, speciation, hygroscopic properties, and their activation characteristics to become cloud condensation nuclei $(\mathrm{CCN})$ or ice nuclei (IN) must be inferred from aerosol chemistry, which itself is going through extensive validation and algorithm improvements (Benedetti et al., 2011). The ultimate task, to better simulate climate, and its response to aerosol direct and indirect effects, is far from trivial, because aerosol-cloud interactions involve a multitude of scales, many of which are at the subgrid and cloud microphysics scales of a typical climate model. Without the key microphysical and dynamical feedbacks, the benefit of including aerosol-cloud interactions in GCMs is highly constrained as the sensitivity of cloud properties to aerosol becomes strongly biased (Stevens and Feingold, 2009). The importance of aerosol-cloud interaction is also evidenced in cloud seeding experiments, as summarized by Cotton and Pielke (1995), who conclude that there is a limited window of opportunity to produce precipitation, rendering cloud seeding exercises to turn into hit or miss ventures. One easily infers that, to obtain an observationally verifiable impact of aerosols on simulated weather or climate, the atmospheric aerosols must be provided realistically at the scale of a cloud.

Besides aerosol activation to form $\mathrm{CCN}$ and IN, McRAS-AC, the chosen cloud scheme, has a parameterization for the subgrid-scale cloud motion fields, vertically varying cloud mass flux with entrainment (and detrainment) from (into) the ambient environment. McRASAC parameterizes cloud-scale mass flux, vertical velocity and condensation-heating-induced updraft and rainevaporation-induced downdrafts. Together with an appropriate precipitation microphysics scheme, McRAS-AC 
becomes a comprehensive cloud-aerosol-precipitation interaction scheme. In Sect. 2.2, we will discuss how McRAS has the unique ability to parameterize the cloud-scale processes described above. The question we seek to answer here is whether McRAS-AC is a viable option for simulating realistic cloud optical properties and climate with the GEOS-5 AGCM.

Simulation of mixed phase clouds in AGCMs is one of the greatest challenges. The goal is realistic prediction of liquid and ice mass fractions, CP effective sizes, and apportionment of precipitation formed by autoconversion, accretion and aggregation into liquid and snow mass fractions and the respective particle numbers. Based on the vertical velocity and entrainment rate, IN determine the cloud ice particle numbers. In addition we perform mass transfer from liquid to ice particles by Bergeron-Findeisen process (Bergeron, 1935) in the following manner. At subfreezing temperatures, the vapor pressure differences over cloud water and ice cloud particles are large enough to create a substantial vapor pressure gradient to induce mass transfer between liquid and ice cloud particles through the intervening atmosphere. Simultaneously, precipitating hydrometeors collect cloud water/ice particles in fall through the cloud (sometimes even from clear air if it happens to be supersaturated with respect to precipitating snow/ice). In this way, precipitation removes cloud particle mass and reduces the in-cloud CPNC. Altogether, these processes add up to make the sink term of CPs for which each of the components must be parameterized. The sum of sources and sinks yields the time rate of change of mass and/or number concentration as shown in the mass and CP number budget equations of the kind shown in Morrison and Gettelman (2008). To close the system, one also needs a precipitation microphysics scheme. Thus, an end-to-end aerosolcloud interaction parameterization needs to perform aerosol activating to create $\mathrm{CCN}$ and/or IN to receive condensation and/or ice deposition or nucleate cloud water through contact or immersion freezing. It also needs a treatment of mass transfers among liquid, ice and vapor phases of cloud water with precipitation microphysics for liquid and ice clouds.

Section 2 gives a brief description of GEOS-5 AGCM hosting McRAS-AC as one of its options. Section 3 presents the simulation experiments. Section 4 provides simulation results. Section 5 has summary and conclusions and suggested research directions to make McRAS-AC simulations even more realistic.

\section{Cloud schemes: GEOS-5 GCM and McRAS-AC}

\subsection{GEOS-5 GCM}

The Fortuna version of the GEOS-5 AGCM used in our study is documented by Molod et al. (2012) who describe the performance of the model with the new updates to the earlier MERRA version (Reinecker et al., 2008). Briefly, the model employs the relaxed Arakawa-Schubert scheme (RAS; Moorthi and Suarez, 1992) for moist convection with Probability Density Functions (PDFs) of cloud water for cloud microphysics. RAS produces prognostic cloud cover, and diagnostic cloud ice and liquid mixing ratios. Other moist algorithms comprise of large-scale condensation and evaporation, auto-conversion and accretion of cloud water and ice, sedimentation of cloud-ice, and reevaporation of falling precipitation following Bacmeister et al. (2006). Longwave radiative transfer calculations are described in Chou et al. (2001), while shortwave radiative transfers are documented in Chou and Suarez (1999). The radiation schemes handle interactions with simulated cloud water, water vapor, and externally prescribed trace gases. In addition, shortwave calculations account for absorption, scattering and transmission by aerosols. For more details, refer to Molod et al. (2012) and Reinecker et al. (2008). We will refer to the GEOS-5 AGCM as the baseline model and/or AGCM.

\subsection{McRAS-AC}

The latest version of McRAS (Sud and Walker, 2003a) is selected as the cloud scheme for including the aerosol-cloud interaction module(s). McRAS uses the moist convective framework of RAS (Moorthi and Suarez, 1992). The first version of McRAS used cloud precipitation microphysics of Sundqvist (1988), and Tiedtke (1993) for computing the time rate of change of cloud water together with parameterizations for rain evaporation (Sud and Molod, 1988) and convective downdrafts (Sud and Walker, 1993). It was extensively evaluated in several single column model intercomparisons (e.g., Ghan et al., 2000; Xie et al., 2002; Xu et al., 2005; Klein et al., 2009; Morrison et al., 2009). Its climate simulations within the GEOS-2 GCM (Sud and Walker, 1999b) were more realistic than that of the baseline cloud scheme of GEOS-2 AGCM. It produced more realistic structures of intra-seasonal oscillations (ISOs) in GEOS-2 and GEOS-3 AGCMs. The ISOs were also well reproduced in the NCAR implementation of McRAS (Maloney and Hartmann, 2001). Nevertheless, these applications also exposed some weaknesses that were addressed by subsequent upgrades (Sud and Walker, 2003a, b), namely a new boundary layer cloud scheme, quadratic entrainment replacing the original linear entrainment. Without knowledge of cloud liquid (or ice) particle number concentration, LPNC (or IPNC), McRAS used empirical equations by Sundqvist (1988) to estimate precipitation generation rates as a function of total cloud water, ambient temperature, and cloud type. For radiation, prescribed in-cloud CPNCs were assumed for land and ocean following Del Genio et al. (1996), while the volume and effective radii of CPs were estimated from another set of empirical assumptions (Sud and Walker, 1999a).

The aerosol-cloud interaction microphysics modules were added to create an upgraded McRAS-AC (Sud and Lee, 2007). One major addition to the present version 
of McRAS-AC is the option to choose Barahona and Nenes (2009a) as an alternative to Liu and Penner (2005) ice nucleation. Thus, the present version of McRAS-AC consists of the McRAS cloud-scheme, plus Fountoukis and Nenes (2005) aerosol activation parameterization to yield $\mathrm{CCN}$, and Barahona and Nenes (2009a) scheme for ice nucleation. For precipitation microphysics, Sud and Lee (2007) parameterization is used for liquid, and Sundqvist (1988) parameterization is used for mixed and ice phase precipitation. In-cloud evaporation and/or precipitation and self collection of cloud water are parameterized following Sud and Lee (2007), who reformulated Seifert and Beheng (2001, 2006) parameterization of precipitation microphysics to accommodate thicker cloud-layers encountered in a coarse resolution GCM. Any change in cloud mass by condensation/deposition and subsequent removal by precipitation works interactively through an implicit backward numerical integration that approximates the solution of the coupled nonlinear differential equations that otherwise would require iteration. Even though McRAS-AC still uses the Sundqvist (1988) parameterization for generating precipitation from mixed phase and ice phase clouds, Barahona and Nenes (2009a, b) ice nucleation and BergeronFindeisen cloud water-to-ice mass transfer (Rotstayn et al., 2000) allow separation of cloud liquid and ice mass fractions with respective LPNC and IPNC. Nevertheless, CPNC $(=\mathrm{LPNC}+\mathrm{IPNC})$ reduction by precipitation is non-linear and is based on a curve-fitted relationship between cloud mass and number concentration for the prescribed gamma distribution of cloud particle sizes. Homogenous freezing of in-cloud liquid drops surviving up to $-38^{\circ} \mathrm{C}$ or beyond is enforced through instantaneous freezing. Synthesis of the above processes provides an end-to-end treatment of prognostic cloud water mass (apportioned between liquid and ice), CPNC, and precipitation produced as a mixture of liquid and snow hydrometeors. The present implementation is shown as a block diagram in Fig. 1. It shows that aerosol activation by vertical ascent or its equivalent cooling creates condensate, $\mathrm{CCN}$ and/or IN, whereas cloud-scale microphysics creates precipitation and reduces CPNC.

McRAS generates three types of prognostic clouds: (i) stratiform or large-scale, (ii) moist convective towers topped by detraining convective anvils that transform into large-scale clouds on the prescribed timescale of an hour, and (iii) boundary layer clouds, mostly a by-product of the detraining dry convective plumes following Stull (1988, p. 11). The stratiform and convective cloud sub-models were transplanted into the GEOS-5 AGCM replacing their counterpart cloud parameterization(s). However, the original planetary boundary-layer (PBL) parameterization of the GEOS-5 AGCM was retained. This circumvents the coupling issues among the PBL cloud interactions, PBL-turbulence parameterization, and land scheme (catchment model, Koster et al., 2000) of the GEOS-5 AGCM. Clearly, the PBL clouds rely on increasing relative humidity to form clouds.

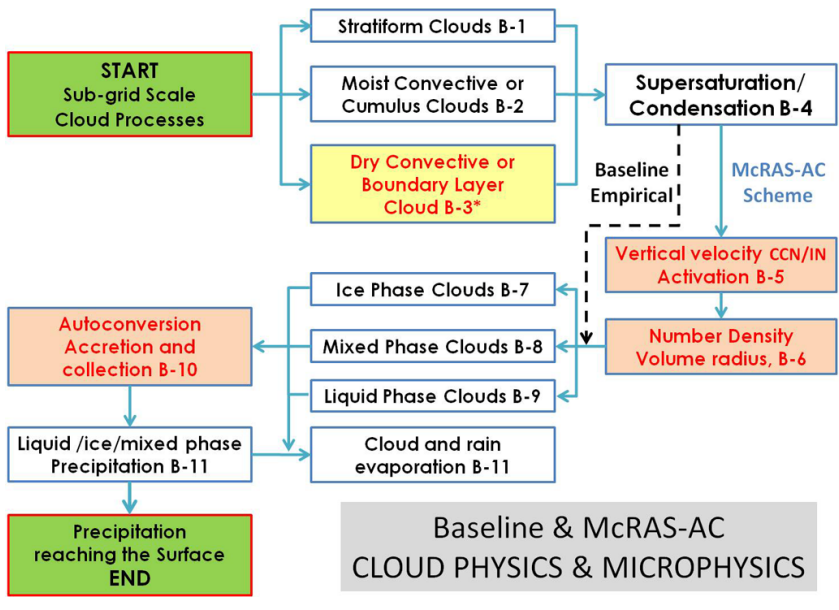

Fig. 1. Block diagram showing key modules of the baseline and McRAS-AC cloud schemes. Convective clouds are parameterized (B-1) in both schemes following RAS and McRAS; stratiform clouds are based on critical RH (B-2), but there are some differences. Explicit dry convection (B-3*) is not yet implemented in GEOS-5. Supersaturation condensation (B-4) activates aerosols in McRAS-AC, to yield CCN or IN and hence CPNC and $r_{\text {vol }}$ (B$5,6)$; in contrast, the baseline scheme circumvents aerosol activation. Both schemes handle all three phases of clouds $(\mathrm{B}-7,8,9)$ except that McRAS-AC bases them on aerosols involving CCN-IN interactions, while the baseline scheme obtains them empirically. In both schemes, Sundqvist (1988)parameterization is used for precipitation rate $(\mathrm{B}-10,11)$ except for liquid clouds where McRAS-AC uses the double moment scheme of Sud and Lee (2007). Rain evaporation and cloud dissipation are parameterized in both schemes. Orange boxes reflect modules with major differences between the two schemes. Green blocks are self-explanatory.

In McRAS-AC, the aerosol activation is fully prognostic. It is a function of rising relative humidity and condensation rates, whereas the aerosol activation to form CCNs depends upon the maximum supersaturation reached (Fountoukis and Nenes, 2005). In convective clouds, all the cloud physics processes are performed at each vertical level and are a function of in-cloud vertical velocities amplified by turbulent velocities. To obtain the convective cloud particle acceleration, the net buoyancy force (a vector sum of all the forces on the cloud) is determined by conservative mixing of mass, momentum, and enthalpy fully accounting for entrainment and/or detrainment to obtain the thermal buoyancy of the convective cloud-scale motions. The parameterization invokes thermal buoyancy forces by condensation heating minus the drag forces of the in-cloud condensate carried aloft and the falling precipitation traversing through. The stratiform clouds are assumed to remain within the layer; hence the moist cloud and precipitation microphysics operates through the entire model-physics time step.

Some key tuning elements of McRAS-AC are as follows. (i) The fall velocity of auto-converted hydrometeors is related empirically to cloud water amount as formulated 
Table 1. Parameterizations in GEOS-5 GCM and McRAS-AC cloud scheme(s).

\begin{tabular}{lll}
\hline Model Specifications & Baseline GEOS-5 GCM & McRAS-AC in GEOS-5 GCM \\
\hline $\begin{array}{l}\text { Deep convection } \\
\text { Stratiform cloud }\end{array}$ & RAS; Moorthi and Suarez (1992) & McRAS; Sud and Walker (1999a) \\
Precipitation liquid & Reinecker et al. (2008) & Sud and Walker (1999a) \\
Precipitation snow & Reinecker et al. (2008) & Sud and Lee (2007) \\
Rain evaporation & Bacmeister et al. (2006) & Sundqvist (1988) \\
Cloud microphysics & Single moment microphysics & Sud and Molod (1988) \\
Cloud scaling & Convective cloud fraction scaled; & Double moment microphysics \\
& Reinecker et al. (2008). & Water path scaled by "Cahalan factor"; Sud and \\
Aerosol effects & Direct effects only & Walker (1999a) \\
CCN activation & Not included & Both direct and indirect effects. \\
IN activation & Not included & Fountoukis and Nenes (2005) \\
Liquid particle number & CP effective radius determined as a function of & BPNC tendency budget of sources and sinks. \\
concentration (LPNC) & $T$ and $P$ & Larahona and Nenes (2009a) \\
Ice particle number & Not included; effective radius determined as a & IPNC tendency budget of sources and sinks. \\
concentration (IPNC) & function of $T$ and $P$ & \\
Cloud liquid mass & Empirical equation for cloud water mass & Cloud liquid mass tendency equation minus \\
floud Ice mass & Total cloud mass minus liquid mass & Bergeron-Findeison (BF) loss. \\
& & Cloud ice mass tendency equation plus BF gain.
\end{tabular}

by Sud and Lee (2007); this assumption is needed to estimate the time taken by the precipitating hydrometeors to accrete and collect in the cloud-layer. (ii) The minimum temperature for IN activation is prescribed, because thus far no physically based algorithms are available. According to Khvorostyanov and Curry (2005), deliquescence-freezing nucleation may occur at water supersaturation in the range of $-5^{\circ} \mathrm{C}$ to $-20^{\circ} \mathrm{C}$, but recent cloud chamber experiment data from Kulkarni and Dobbie (2010) showed water supersaturation ranging between $5-10 \%$ for different IN species and this represents $\mathrm{a}-5^{\circ} \mathrm{C}$ to $-10^{\circ} \mathrm{C}$ temperature range. Indeed, our current choice of $-8^{\circ} \mathrm{C}$, based on brute force tuning to obtain the observed pattern of the zonal mean ice cloud fractions, falls right in the middle of the Kulkarni and Dobbie (2010) estimates. (iii) Invoking the so-called "Cahalan factor" accounts for cloud horizontal inhomogeneity on the reflected solar radiation. (iv) There is neglect of the time delay between maximum supersaturation and associated aerosol activation. This could be expected to generate excessive in-cloud $\mathrm{CCN}$, but it is unavoidable because all physical processes in GCMs assume quasi-static equilibrium, and (v) neglect of giant CCNs (Barahona et al., 2010) helps to reduce the excessive cloudiness over land where most giant CCNs form primarily through anthropogenic activity. In future, we plan to revisit these tuning elements as well as the aerosol input and CCN activation to optimize the "AC part" of McRAS.

\section{Simulation experiments}

Table 1 summarizes key differences between the two cloud microphysics schemes now available as options in the Fortuna version of the GEOS-5 AGCM (referred to as "baseline model"). The present goal is to determine if McRASAC can yield realistic liquid and ice clouds in the AGCM and whether McRAS-AC can be used to perform simulation studies of the influence of aerosols on cloud microphysics and CREs. We performed two 10-yr-long simulations: one with the GEOS-5 AGCM with its own cloud scheme (hereafter referred to as "CTL"), and one with the newly implemented McRAS-AC replacing the GEOS-5 AGCM's cloud physics module (hereafter, referred to as "MAC"). Both simulations were started from the analyzed initial conditions for 1 May 1993 and were run out to 31 December 2003. However, the first eight months of the simulation, i.e., up to $31 \mathrm{De}-$ cember 1993, were ignored as the initial adjustment period; only last 10-yr data, from 1 January 1994 to 31 December 2003, were used for assessing the performance of the two cloud schemes. The monthly climatology of aerosols was taken from GOCART, Goddard Chemistry Aerosol Radiation and Transport (Chin et al., 2002), and is based on extensive aerosol model development and calibration/validation exercises (Colarco et al., 2010). Currently McRAS-AC uses five externally mixed aerosols: sulfates, sea-salt, mineral dust, black carbon and organic carbon. GOCART provides the time-dependent mass of each aerosol species, which is further divided among different modes that are sorted by size, from which the aerosol numbers are calculated by making sectionals of aerosols as a function of supersaturation needed for forming CCN (Nenes and Seinfeld, 2003). 
Table 2. Descriptions of simulation experiments.

\begin{tabular}{llr}
\hline $\begin{array}{l}\text { Simulation } \\
\text { Experiments }\end{array}$ & Descriptions & $\begin{array}{r}\text { Years } \\
\text { Analyzed }\end{array}$ \\
\hline Control run (CTL) & GEOS-5 GCM with baseline cloud physics & 10 \\
McRAS-AC run (MAC) & GEOS-5 GCM with the new McRAS-AC cloud physics & 10 \\
CTL run with COSP simulator included & Cloud properties from ISCCP and MODIS simulators & 1 \\
MAC run with COSP simulator included & Cloud properties from ISCCP and MODIS simulators & 1 \\
MAC run with half the sea salt particle size & McRAS-AC with half size sea salt (eight times number density) & 1 \\
Interactive GOCART with baseline cloud scheme & Interactive GOCART with McRAS-AC & 1 \\
\hline
\end{tabular}

The fluxes at the Earth's surface are parameterized differently over land, ocean and snow cover or sea ice. For oceanic grid cells, sea surface temperatures (SSTs) are prescribed from the Reynolds et al. (2002) analysis. The data comprise of a series of monthly SST datasets from which daily SST are linearly interpolated (and held constant over each day) at each grid cell. Sea ice is prescribed similarly from sea-ice data analysis. The land scheme of the GEOS-5 AGCM is due to Koster et al. (2000) and has been described in Reinecker et al. (2008). It uses monthly climatology of prescribed vegetation phenology and morphology with a detailed catchment structure of land, soil moisture, and surface fluxes. The soil moisture is fully interactive with a simple but quite extensively validated parameterization for surface flow and baseflow generating the runoff. To see more details of some of the more recent upgrades of the model, the reader should refer to Molod et al. (2012).

Two sensitivity studies to better understand the cause of large biases in CREs in MAC simulation, specifically to determine its response to prescribed size of sea salts and interactive versus prescribed aerosols, were conducted. To isolate the intrinsic biases introduced by comparing the straight model output with the ISCCP and/or MODIS satellite data, two additional 1-yr test-runs with the addition of ISCCP and MODIS simulators of the Cloud Feedback Model Intercomparison Project Observational Simulator Package (COSP, http://cfmip.metoffice.com/COSP.html) were invoked into the CTL and MAC model configurations. These experiments are listed in Table 2 and analyzed in the next section.

\section{Results}

A comparison of two 10-yr-long model integrations, one called MAC and one called CTL, helps to distinguish how precipitation, clouds, their water paths, effective radii, and CREs vary between the runs. Both simulations were made without the COSP simulator package, whose implementation maturity in GEOS-5 needs optimization and evaluation. Nevertheless, at the behest of one of the reviewers and to gain a different perspective on the biases between the modeled and satellite-inferred cloud fields, the MODIS and ISCCP simulators of the COSP package were included into the GCM to perform two 1-yr runs for the CTL and MAC cloud schemes. We distinguish between two aspects of the intercomparison: one is the differences due to cloud parameterization schemes, in CTL and MAC; the other is the influence of aerosol activation and associated cloud particle numbers and sizes in MAC simulation since the cloud liquid and ice particle effective radii are empirically prescribed as functions of temperature and pressure in CTL.

The goal is to determine how MAC and CTL cloud and precipitation climatologies compare with each other and how biased they are against observations. Is the annual cycle of CRE bias-free, and how far can these results help us trust model simulated climate change scenarios? The strategy is to determine MAC seasonal climatology and its biases and thereafter design upgrades to ameliorate them. Second, are there sensitivities to uncertainties in aerosol mass and number concentration of the real environment, and can these uncertainties help us tune model's CRE to better simulate the influence of aerosols on clouds, cloud-radiation interactions and their consequences on the regional climate change? We produced MAC and CTL seasonal fields for DJF, MAM, JJA, SON and annual means (ANN) for several key quantities. However, to limit the number of figures, we show only the climatology of the two extreme seasons, DJF and JJA, and their annual means. Whereas revising the algorithms and making aerosol input modifications to ameliorate some of the biases are left for the future, nevertheless we include two test runs showing the potential for eliminating two major biases of McRAS-AC simulated clouds. Some key highlights of model performance and our sensitivity tests are as follows.

\subsection{Precipitation fields}

The left two panels of Fig. 2 depict the broad feature of precipitation climatology of MAC and CTL. Both modelsimulations have good Intertropical Convergence Zone (ITCZ) and South Pacific Convergence Zone (SPCZ), with intense convective precipitation, as must be expected. In DJF a large amount of precipitation is simulated over the South American landmass, Australia, the tropical islands of Southeast Asia, over the North Atlantic along the eastern boundary of Asia, and over the Gulf Stream along the eastern boundary of North America. Large amount of precipitation also occurs 


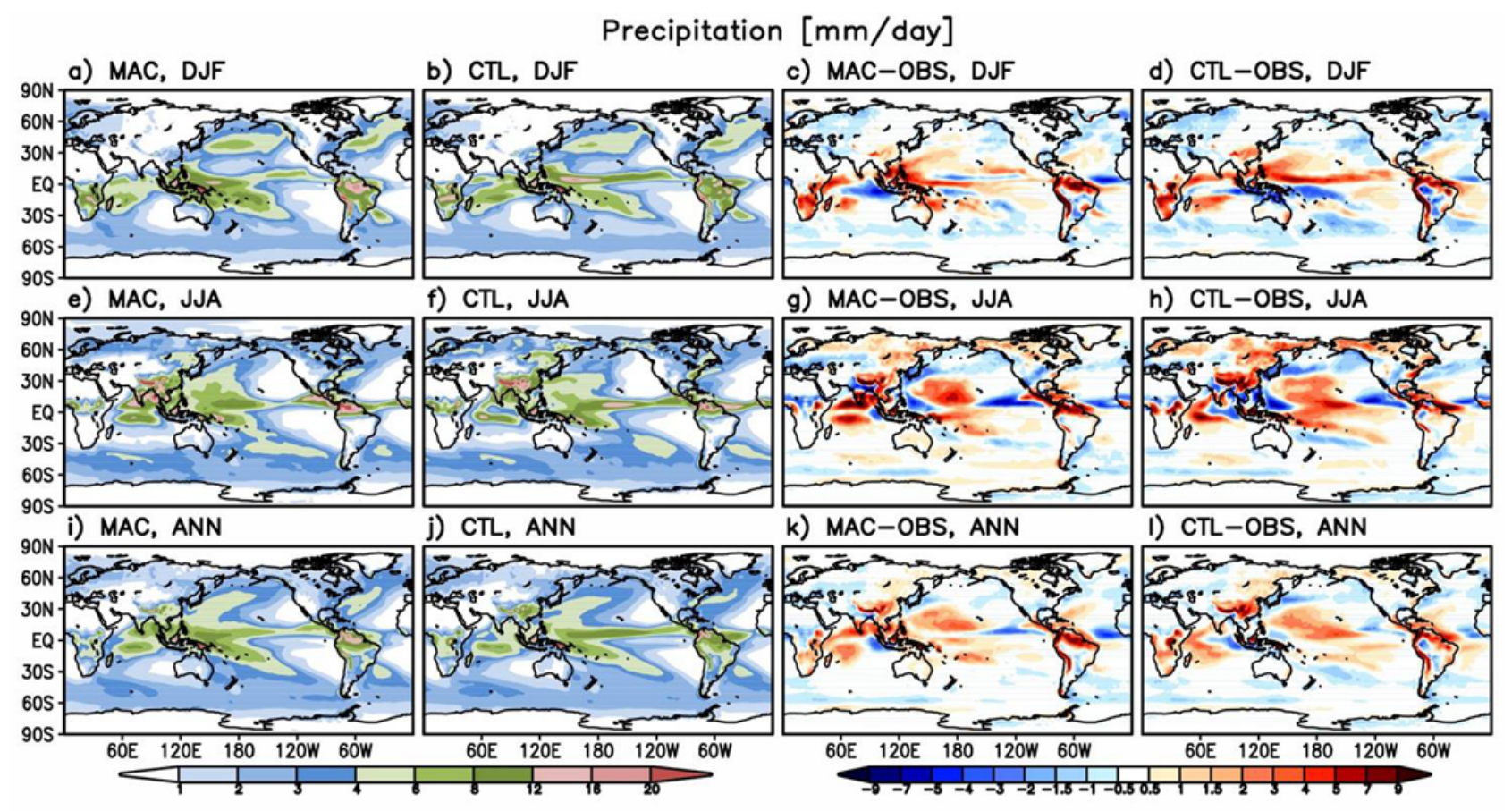

Fig. 2. Simulated $10-y r$ mean precipitation ( $\mathrm{mm}^{-1} \mathrm{yy}^{-1}$ ) for DJF (top), JJA (middle), and ANN (bottom) in MAC and CTL runs (left 2 panels) and MAC minus OBS and CTL minus OBS (right two panels); GPCP data represent OBS.

over the rising branch of the Ferrel cell between $40^{\circ} \mathrm{S}-60^{\circ} \mathrm{S}$. In JJA, we see copious tropical rainfall that includes the ITCZ. The simulated tropical Pacific ITCZ has some biases; it is somewhat weaker (with less than observed rainfall intensities) in the mid-span of the ITCZ band and somewhat more than the observed near and over the land masses at both ends of the ITCZ band, presumably due to orographic intensification of precipitation, a well-known GEOS-5 GCM bias. Consequently, more water vapor converges on to land away from its natural location(s) over the tropical Pacific Ocean, where the model simulated climatology has a rainfall deficit. Indian and Asian regions have realistic monsoons and associated rainfall but shown some Himalayan orography caused biases. Northwards of Sahel, the Sahara desert is dry in JJA as it should. Generally, MAC and CTL biases in precipitation are quite similar to each other, although MAC does better on the RMSE scores in DJF and JJA but not in the ANN (see Table 3). The majority of the biases are associated with orographic intensification of precipitation and its related moisture convergences, a proverbial problem for GEOS-5 GCM and a number of numerical models. Bangert et al. (2011) suggest use of orographic uplift as a "pseudo-updraft velocity" superposed on the vertical velocity normally resolved by the model as a solution. However, according to Chao (2012), the problem has been largely solved in an experimental version of the GEOS-5 AGCM runs with mixing of surface air aloft by orographic uplift, but Chao's parameterization is not yet implemented in the Fortuna version of GEOS-5 AGCM employed in the present study. Excessive precipitation biases along southern Andes, hilly regions of southern Africa, and tropical islands of Southeast Asia are seen in DJF. Precipitation biases around eastern regions of Himalayas, and Andes through South and Central America (redder regions in the difference maps, Fig. 2) are also conspicuous. In MAC or CTL simulation minus observations, the precipitation biases are more positive over the tropical Pacific ITCZ in CTL visà-vis MAC, whereas the biases are quite similar in the JJA over the tropical Pacific ITCZ except that lighter colors in MAC minus OBS (observations) mean that the corresponding biases are less in MAC. Overall, both simulations, MAC and CTL, compare well with the GPCP (Global Precipitation Climatology Project) precipitation data (Adler et al., 2003). In the boreal winter (DJF) season, MAC (CTL) simulates global mean precipitation of $2.89(2.84) \mathrm{mm} \mathrm{day}^{-1}$ versus the somewhat smaller value of $2.68 \mathrm{~mm} \mathrm{day}^{-1}$ in the GPCP data. The corresponding boreal summer (JJA) values are 3.01 (3.04) $\mathrm{mm} \mathrm{day}^{-1}$ versus $2.71 \mathrm{~mm} \mathrm{day}^{-1}$ in the GPCP data. Indeed, the simulated precipitation values are consistent with global mean surface evaporation. Accordingly, global condensation heating of McRAS-AC is $6.0(8.7) \mathrm{W} \mathrm{m}^{-2}$ too large in DJF (JJA). Since SSTs are prescribed, excessive evaporation over the oceans can occur without any (negative) feedback that could reduce the SSTs and its associated surface evaporation (see Table 3 for the details).

DJF averages in the tropics show that the MAC (CTL) rainfall distribution over the sharp ITCZ is less (more) 
Table 3. Select global means of MAC and CTL simulations versus observations.

\begin{tabular}{|c|c|c|c|c|c|c|c|c|c|}
\hline \multirow{2}{*}{ DATA/Periods Fields } & \multicolumn{3}{|c|}{ *OBS: Observed Mean } & \multicolumn{3}{|c|}{ MAC: Mean/(RMSE) } & \multicolumn{3}{|c|}{ CTL: Mean/(RMSE) } \\
\hline & DJF & JJA & ANN & DJF & JJA & ANN & DJF & JJA & ANN \\
\hline $\begin{array}{l}\text { Precipitation } \\
\left(\mathrm{mm} \mathrm{day}^{-1}\right)\end{array}$ & 2.68 & 2.71 & 2.68 & $\begin{array}{l}2.89 \\
(1.54)\end{array}$ & $\begin{array}{l}3.01 \\
(1.87)\end{array}$ & $\begin{array}{l}2.92 \\
(1.32)\end{array}$ & $\begin{array}{l}2.84 \\
(1.58)\end{array}$ & $\begin{array}{l}3.05 \\
(1.92)\end{array}$ & $\begin{array}{l}2.89 \\
(1.29)\end{array}$ \\
\hline $\begin{array}{l}\text { Total cloud fraction } \\
\text { Default model }(\%)\end{array}$ & \multirow[t]{2}{*}{67.0} & \multirow[t]{2}{*}{65.5} & \multirow[t]{2}{*}{66.4} & $\begin{array}{l}56.7 \\
(17.1)\end{array}$ & $\begin{array}{l}55.0 \\
(16.6)\end{array}$ & $\begin{array}{l}55.6 \\
(15.8)\end{array}$ & $\begin{array}{l}44.3 \\
(25.6)\end{array}$ & $\begin{array}{l}44.8 \\
(24.8)\end{array}$ & $\begin{array}{l}44.5 \\
(24.3)\end{array}$ \\
\hline Total cloud fraction & & & & $\begin{array}{l}(17.1) \\
57.4\end{array}$ & $\begin{array}{l}(10.0) \\
56.1\end{array}$ & $\begin{array}{l}(15.8) \\
56.9\end{array}$ & $\begin{array}{l}(25.0) \\
39.8\end{array}$ & $\begin{array}{l}(24.8) \\
41.1\end{array}$ & $\begin{array}{l}(24.3) \\
40.6\end{array}$ \\
\hline ISCCP simulator (\%) & \multirow{4}{*}{21.9} & \multirow{4}{*}{21.9} & \multirow{5}{*}{21.7} & $(16.8)$ & $(16.5)$ & $(14.8)$ & $(29.5)$ & $(28.0)$ & $(27.7)$ \\
\hline High cloud fraction & & & & 21.6 & 22.4 & 22.3 & 22.6 & 23.2 & 23.1 \\
\hline Default model (\%) & & & & $(8.9)$ & $(9.3)$ & $(6.6)$ & $(8.9)$ & $(9.8)$ & $(7.6)$ \\
\hline High cloud fraction & & & & 26.3 & 25.7 & 26.4 & 23.6 & 23.6 & 23.5 \\
\hline ISCCP simulator (\%) & \multirow{4}{*}{19.6} & \multirow{4}{*}{17.7} & & $(12.1)$ & $(11.3)$ & $(9.9)$ & $(9.8)$ & $(10.8)$ & $(8.2)$ \\
\hline Middle cloud fraction & & & \multirow{2}{*}{19.2} & 21.9 & 19.2 & 20.5 & 9.9 & 9.9 & 9.8 \\
\hline Default model (\%) & & & & $(9.3)$ & $(7.4)$ & $(6.7)$ & (13.3) & (10.8) & (11.5) \\
\hline Middle cloud fraction & & & & 15.6 & 14.0 & 14.8 & 5.9 & 6.1 & 5.8 \\
\hline ISCCP simulator (\%) & \multirow{5}{*}{24.9} & \multirow{5}{*}{26.6} & \multirow{5}{*}{25.6} & $(10.3)$ & $(9.7)$ & $(9.1)$ & $(16.9)$ & $(14.5)$ & $(15.5)$ \\
\hline Low cloud fraction & & & & 37.0 & 35.4 & 35.9 & 22.0 & 22.8 & 22.2 \\
\hline Default model (\%) & & & & $(21.2)$ & $(18.5)$ & $(19.8)$ & $(13.7)$ & $(17.4)$ & $(13.1)$ \\
\hline Low cloud fraction & & & & 16.1 & 16.7 & 16.3 & 14.8 & 15.8 & 15.4 \\
\hline ISCCP simulator (\%) & & & & $(13.3)$ & $(15.8)$ & $(13.1)$ & $(14.9)$ & $(16.8)$ & $(14.9)$ \\
\hline \multirow{2}{*}{$\begin{array}{l}\text { Model's grid mean LWP } \\
\left(\mathrm{g} \mathrm{m}^{-2}\right)\end{array}$} & \multirow[t]{2}{*}{84.3} & \multirow[t]{2}{*}{85.8} & 84.3 & 76.6 & 84.2 & 79.4 & 72.9 & 74.5 & 72.4 \\
\hline & & & & $(40.1)$ & $(44.9)$ & $(34.1)$ & $(26.4)$ & $(33.2)$ & $(24.2)$ \\
\hline MODIS simulators in-cloud LWP & 108.7 & 112.0 & 107.0 & 113.4 & 135.7 & 129.8 & 246 & 264.5 & 253.5 \\
\hline$\left(\mathrm{g} \mathrm{m}^{-2}\right)$ & & & & $(67.7)$ & $(72.9)$ & $(60.0)$ & $(212)$ & $(226)$ & $(212)$ \\
\hline Model's grid mean TWP & 89.9 & 90.5 & 88.2 & 92.1 & 107.0 & 98.3 & 77.2 & 82.4 & 77.8 \\
\hline$\left(\mathrm{g} \mathrm{m}^{-2}\right)$ & & & & $(51.4)$ & $(65.1)$ & $(41.1)$ & $(59 / 8)$ & (57.9) & $(48.7)$ \\
\hline MODIS simulators in-cloud IWP & 228.8 & 248.6 & 243.8 & 184.6 & 214.0 & 198.3 & 242.3 & 248.6 & 272.9 \\
\hline$\left(\mathrm{g} \mathrm{m}^{-2}\right)$ & & & & $(150)$ & $(138)$ & $(93.1)$ & $(172)$ & $(170)$ & $(137)$ \\
\hline Cloud-ice effective radius model & & & & 29.9 & 28.3 & 28.6 & 21.5 & 21.9 & 21.6 \\
\hline Default $(\mu \mathrm{m})$ & 24.8 & 25.6 & 25.2 & $(8.8)$ & $(9.3)$ & $(7.1)$ & $(4.5)$ & $(6.8)$ & $(4.4)$ \\
\hline Cloud-ice effective radius MODIS & & & & 21.6 & 21.7 & 20.5 & 21.6 & 22.0 & 22.0 \\
\hline simulator $(\mu \mathrm{m})$ & & & & $(6.3)$ & $(7.2)$ & $(5.7)$ & $(4.3)$ & $(4.0)$ & $(3.6)$ \\
\hline Cloud-drop effective radius model & & & & 14.3 & 14.4 & 14.0 & 10.1 & 10.5 & 10.3 \\
\hline Default $(\mu \mathrm{m})$ & 15.2 & 16.3 & 15.6 & $(4.2)$ & $(4.4)$ & $(3.3)$ & $(6.1)$ & $(7.1)$ & $(6.1)$ \\
\hline Cloud-drop effective radius MODIS & & & & 16.0 & 15.8 & 15.8 & 10.4 & 10.7 & 10.6 \\
\hline simulator $(\mu \mathrm{m})$ & & & & $(3.7)$ & $(3.1)$ & $(2.5)$ & $(5.5)$ & $(6.1)$ & $(5.9)$ \\
\hline Grid average/in-cloud IPNC & & & & $4.1 /$ & $3.5 /$ & $4.1 /$ & & & \\
\hline$\left(\# \mathrm{~cm}^{-3}\right)$ & & & & 10.6 & 9.4 & 10.7 & & & \\
\hline Grid Average/in-cloud LPNC & & & & $35.0 /$ & $44.5 /$ & $44.3 /$ & & & \\
\hline$\left(\# \mathrm{~cm}^{-3}\right)$ & & & & 68.9 & 93.1 & 90.3 & & & \\
\hline Outgoing LW radiation & 236.9 & 243.3 & 239.7 & 236.0 & 242.0 & 238.6 & 237.4 & 245.8 & 241.1 \\
\hline$\left(\mathrm{W} \mathrm{m}^{-2}\right)$ & & & & $(8.7)$ & $(9.8)$ & $(7.0)$ & $(10.3)$ & $(12.1)$ & $(9.0)$ \\
\hline Absorbed SW radiation & 244.5 & 235.7 & 240.5 & 252.2 & 235.3 & 243.3 & 246.7 & 239.0 & 243.0 \\
\hline$\left(\mathrm{W} \mathrm{m}^{-2}\right)$ & & & & $(18.9)$ & $(15.5)$ & $(12.1)$ & $(17.2)$ & $(21.7)$ & $(15.6)$ \\
\hline Net TOA radiation & 7.6 & -7.6 & 0.83 & 16.2 & -6.6 & 4.7 & 9.3 & -6.8 & 2.0 \\
\hline$\left(\mathrm{W} \mathrm{m}^{-2}\right)$ & & & & $(17.5)$ & $(12.4)$ & $(11.1)$ & $(13.4)$ & $(16.3)$ & $(11.2)$ \\
\hline TOA LW CRE & 25.9 & 26.3 & 26.2 & 24.5 & 25.4 & 25.3 & 21.6 & 22.2 & 22.2 \\
\hline$\left(\mathrm{W} \mathrm{m}^{-2}\right)$ & & & & $(7.7)$ & $(7.4)$ & $(6.0)$ & $(9.3)$ & $(10.2)$ & $(8.3)$ \\
\hline TOA SW CRE & -51.6 & -44.8 & -47.3 & -45.6 & -46.7 & -46.3 & -50.8 & -43.2 & -46.4 \\
\hline$\left(\mathrm{W} \mathrm{m}^{-2}\right)$ & & & & $(17.9)$ & $(16.2)$ & $(12.2)$ & $(17.3)$ & $(20.9)$ & $(15.3)$ \\
\hline Net TOA CRE & -25.7 & -18.5 & -21.1 & -21.1 & -21.3 & -21.0 & -28.8 & -21.2 & -24.2 \\
\hline$\left(\mathrm{W} \mathrm{m}^{-2}\right)$ & & & & $(16.9)$ & $(14.2)$ & $(11.3)$ & $(18.4)$ & $(21.0)$ & $(15.2)$ \\
\hline
\end{tabular}

* Datasets deployed: (a) GPCP for precipitation (Adler et al., 2003, version 2.1, 30 yr climatology from 1979); (b) ISCCP for cloud fraction (Rossow and Schiffer, 1999, ISCCP D2 monthly average covered the period July 1983 to June 2008); (c) SSM/I for grid mean liquid water path (Weng et al., 1997, climatology from 1993 to 2002); (d) MODIS for effective radii, grid mean total water path, and in-cloud liquid/ice water path (Platnick et al., 2003, Collection 5.1, MYD08_M3 (monthly 1 deg Aqua) from July 2002 to present); (e) CERES for TOA radiation and CRE (Loeb et al., 2009, version EBAF2.6). 


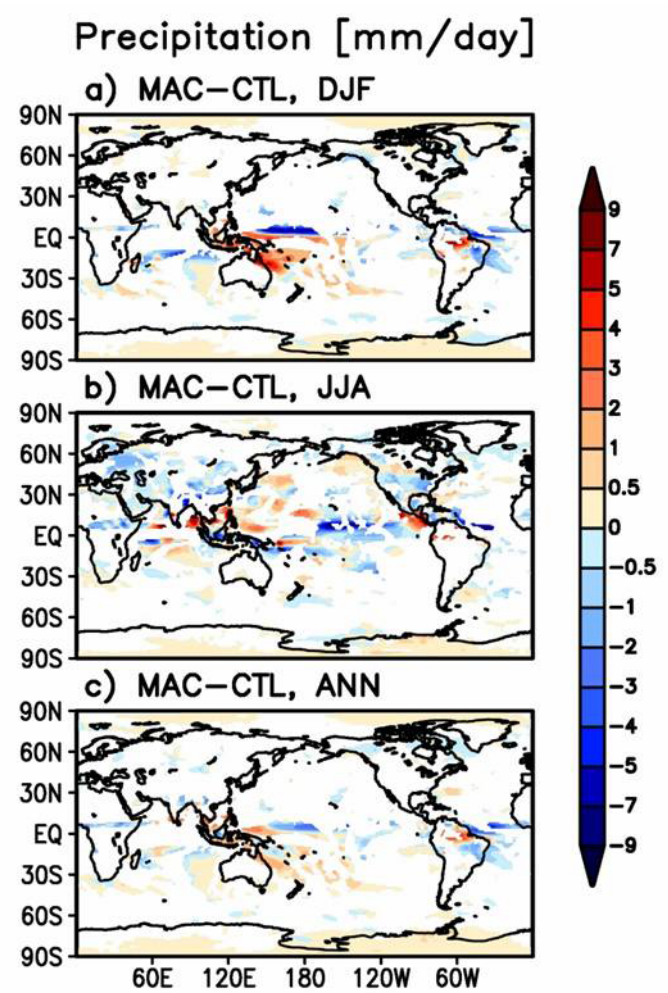

Fig. 3. Statistically significant precipitation differences $\left(\mathrm{mm}_{\mathrm{day}}{ }^{-1}\right.$ ) are color coded: MAC minus CTL for DJF (top), JJA (middle), and ANN (bottom) using a 2-tailed Student's t-test.

intense than the corresponding GPCP data. However, MAC simulations make up for the reduction with small increases over the neighboring grid cells north and south of the ITCZ. The orographic precipitation intensification biases are consistently positive and quite similar in both MAC and CTL simulations. Clearly, the AGCM has a problem reproducing observed precipitation in response to flow across the steep hills. For JJA, both MAC and CTL simulate the equatorial Pacific ITCZ in the middle of its east-west span similarly weak, even though CTL simulation has a slightly better organized ITCZ. On the whole, both cloud schemes show persistent biases that need some attention (Fig. 2, two right panels).

When statistically significant differences between model simulations and observations are examined, the orographically enhanced precipitation biases overwhelm the outcome, but when the analysis is performed on precipitation differences between the two models runs, the areas isolated indicate influences of moist physics only (Fig. 3). Large differences are notable over the tropical ITCZ that includes East Pacific in DJF and mid-Pacific in JJA; some differences are significant over the tropical Atlantic and Indian Ocean in both seasons. In these convergence zones, MAC precipitation is less than that of CTL. Naturally, areas of statistical significance on annual mean fields are even smaller and that is
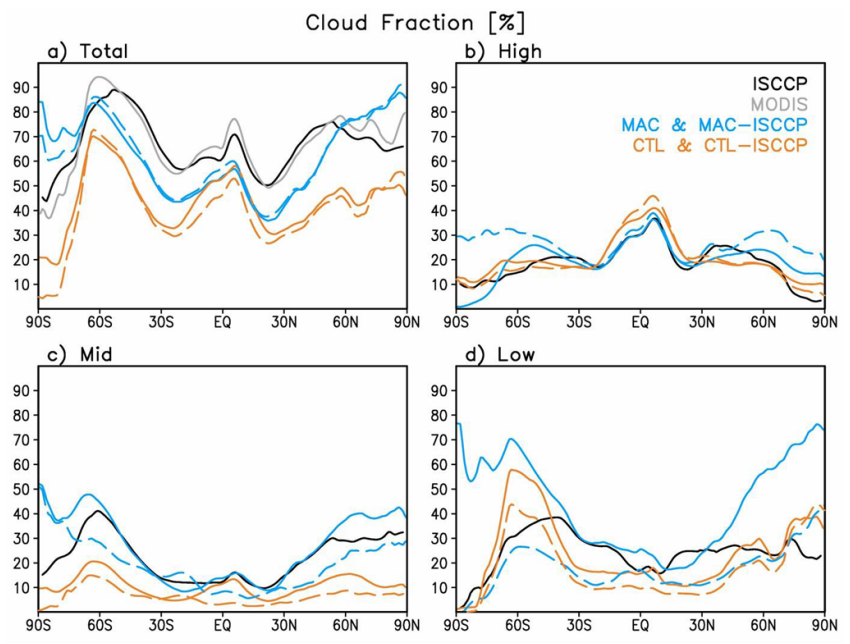

Fig. 4. Annual mean zonal averaged cloud fractions for (a) total column-, (b) high, (c) mid-, and (d) low clouds. Black dark (light) solid curves show cloud fractions in the ISCCP (MODIS) satellite observations; blue solid (dashed) curves are for MAC simulated clouds as seen by the radiative transfer following the Chou et al. (1999) cloud overlap assumptions, whereas the ISCCP simulator curves are dashed. Orange curves are for the corresponding CTL clouds.

consistent with our understanding that biases often reduce by averaging not only over the annual cycle but also across multi-model ensembles even over shorter time periods. Overall, the precipitation differences between MAC and CTL in a 2-tailed Student's t-test at $95 \%$ significance are small and without much structure except for the polar regions. Thus we argue that both schemes produce similar precipitation fields with very similar biases (vis-à-vis the GPCP data) except for the areas of orographic intensification where the biases are large.

\subsection{Cloud fractions and water path}

Cloud fractions, effective radii and water path are the center pieces of cloud optical properties that govern the CRE (Sect. 4.4.2). Hence those are examined extensively here.

\subsubsection{Cloud fractions}

Total cloud fractions calculated by the model's default method, i.e., using Chou and Suarez (1999) cloud overlap assumptions and the ISCCP simulator vis-à-vis ISCCP data (Rossow and Schiffer, 1999), are shown in Fig. 4a and Table 3. The global mean simulated total cloud fractions of MAC are $15 \%$ larger than those of CTL, but still about $10 \%$ less than the observed. Thus, globally averaged biases in the total cloud fraction of CTL are about $25 \%$ less than observed $(66 \%)$. Whereas MAC biases are also negative, they are less than half as large as CTL-biases. The top left column of Fig. 4 shows that the zonal distribution of total clouds 
produced by the model's default method, i.e., the current Chou and Suarez (1999) cloud overlap assumptions, tracks the ISCCP simulator generated clouds remarkably well, particularly in MAC runs, even though there are discernible biases in vis-à-vis ISCCP/MODIS data. MAC total clouds are similar to CTL in the tropics, but they are much larger than CTL at higher latitudes and even exceed satellite observations (ISCCP and MODIS data) in the polar regions (Fig. 4a). If the simulated cloud fractions are far off, the only way to get realistic CRE is to tune cloud water or scale cloud fraction and/or cloud optical properties. Whereas MAC uses cloud water path scaling to account for the subgrid-scale cloud water inhomogeneity, CTL performs convective cloud fraction scaling (Table 1) to optimize its CRE. Total cloud fraction biases can be better understood by looking at the model produced and ISCCP simulator inferred high, middle, and low level clouds versus the satellite retrievals.

High clouds (defined as clouds located above $400 \mathrm{hPa}$ in GEOS-5 according to Chou et al., 1999) are equally robust and realistic in both CTL and MAC simulations except for the polar regions, where MAC high clouds show larger positive biases than the CTL (Fig. 4b). MAC high clouds, according to the ISCCP simulator, exhibit even larger biases over the high latitude regions as compared to the model fields and/or ISCCP data. The underlying reason is that the MAC simulation produces large cloudiness between 400 and $440 \mathrm{hPa}$ particularly at high latitudes as the model simulates deeper clouds. With the high cloud boundary lowered to $440 \mathrm{hPa}$ in the simulator, the cloudiness between 400 $440 \mathrm{hPa}$ is the source of large disagreement between the MAC-ISCCP and Chou et al. (2001) high-cloud fractions. The CTL clouds are much less affected by the $40 \mathrm{hPa}$ shift in its ISCCP simulator, because CTL does not simulate such large cloud fraction in the $400-440 \mathrm{hPa}$ range. On seasonal timescales the biases appear quite different. Some high cloud underestimates over north India, western United States, and Argentina are common to both MAC and CTL simulations in DJF as well as JJA (not shown) leading to discernible signatures in the annual averages. Over the oceans, MAC does better than CTL, which overestimates high clouds. However, high cloud fractions are greater than observed in both MAC and CTL simulations for both DJF and JJA seasons. In DJF, MAC (CTL) simulates about $-0.3 \%(0.7 \%)$ bias for an observed high clouds fraction of about $22 \%$. In JJA MAC (CTL) simulates $0.5 \%(1.3 \%)$ more high clouds and those biases are tolerable in GCM applications. The similarity of high cloud fractions in the tropics is most likely the outcome of both the CTL and McRAS-AC using RAS as the convective scheme. Finally, a word of caution about ISSCP cloud fractions is warranted here. Stubenrauch et al. (2012) state that ISCCP misidentifies high-level clouds overlying lower-level clouds as mid-level clouds; thereby ISCCP clouds data would low-bias the high-level clouds and high-bias the mid-level clouds, and that could, in part, contribute to the high cloud biases as a spurious model deficiency.

The middle level cloud $700-400 \mathrm{hPa}$ range for the model's default method versus 440-680 hPa range used in the COSPISCCP simulator and the ISCCP data appears considerably better in MAC than CTL simulations (Fig. 4c). The mean RMSE errors of MAC (CTL) for DJF, JJA, and ANN averages are much smaller (larger) compared to ISSCP data (see Table 3). Generally, CTL produces much smaller than observed mid-level cloud fractions. MAC biases are $2.2 \%$ for DJF and $1.5 \%$ in JJA versus about $-10.3 \%$ for both DJF and JJA in CTL simulations. The McRAS cloud scheme used in MAC started producing more mid-level clouds after melting of snowfall at $0^{\circ} \mathrm{C}$ was introduced (Sud and Walker, 2003b). In the tropics, the precipitating snow melts at around $500 \mathrm{hPa}$, whereby it produces an inversion and that stops less energetic cumulus towers from penetrating through, thereby forcing them to detrain as cumulus congestus. We should point out that mid-level cloud fractions in the ISSCP data may be too large (Chen and Del Genio, 2008). Moreover, the mid-level cloud percentages are almost the same as the high cloud percentages, but, for the present, MAC simulates them, and our radiation balances suggest that cumulus congestus and midlevel detrainment by high latitude cumulus clouds may be responsible for the better outcome (Johnson et al., 1999).

The low level clouds (surface to $700 \mathrm{hPa}$ for Chou et al. (2001) and surface to $680 \mathrm{hPa}$ for ISCCP simulator and ISCCP data) in MAC simulation are closer to observations than $\mathrm{CTL}$ between $30^{\circ} \mathrm{S}$ to $30^{\circ} \mathrm{N}$, but at higher latitudes MAC suffers large biases particularly in the polar regions, where observations are not so reliable. However, the ISCCP simulator masks low clouds by high and mid-level clouds overlapping them; thereby it makes MAC's low cloud fractions much better than the default method of Chou et al. (2001). Since high clouds over high latitudes are excessive, the low level ISCCP simulator cloud fractions of MAC are smaller than the ISCCP data presumably due to excessive masking. The biases at high latitudes occur in all the seasons as well as the annual means. CTL simulations produce less than observed low-level clouds, but they become better at higher latitudes (Fig. 4d). This is consistent with better high clouds in CTL runs. Overall, CTL-simulated PBL clouds are about $4 \%$ less than the observed. However, in the tropics, MAC simulation is still as good as CTL. The original explicit dry convection scheme of McRAS-AC generated mass flux that transports the surface fluxes aloft and results in PBL eddy to become cloudy if supersaturated at detrainment at PBL inversion. In the current application, we rather let the PBL scheme of the baseline GEOS-5 GCM perform this function; clearly, it needs further examination. Moreover, precipitation in the polar regions often emerges as tiny ice particles from the ice fog falling out of clear sky (diamond dust; Greenler, 1999). McRAS-AC may be designating such layers as cloudy, because the local RH of the ambient atmosphere must exceed the saturation vapor pressure of ice (criteria used to identify 
Total Water Path $\left[\mathrm{g} / \mathrm{m}^{2}\right]$

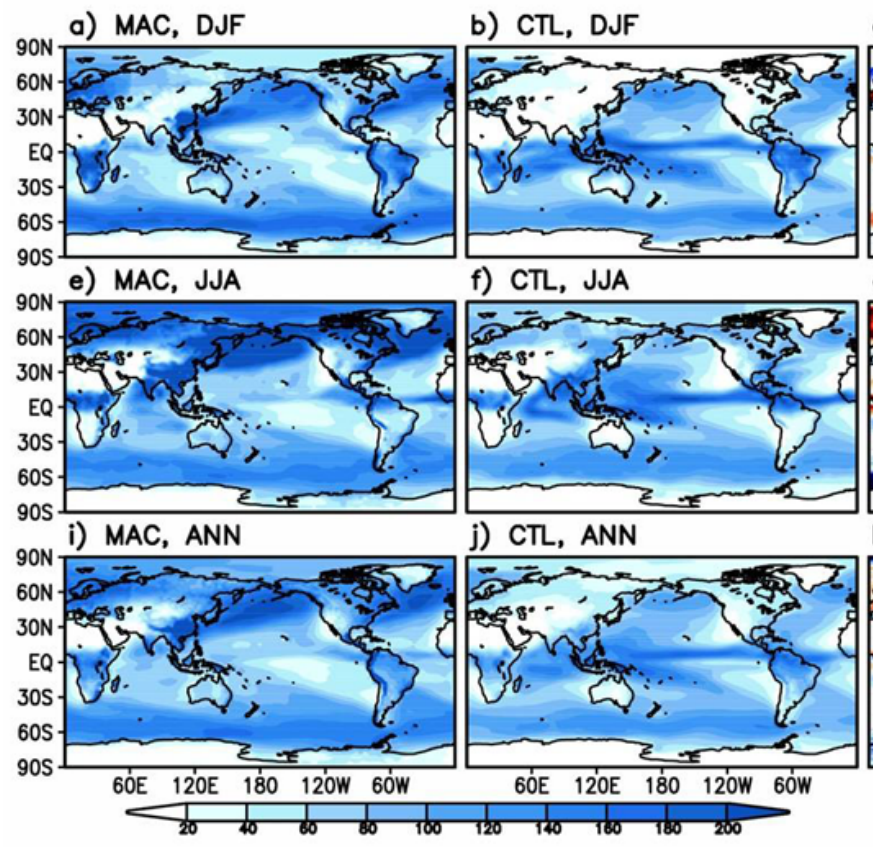

c) MAC-OBS, DJF

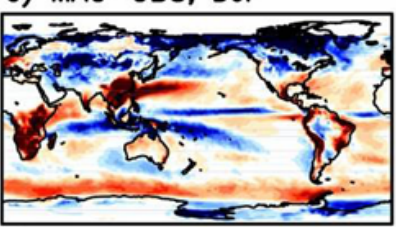

g) MAC-OBS, JJA

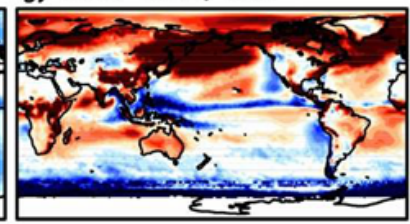

k) MAC-OBS, ANN

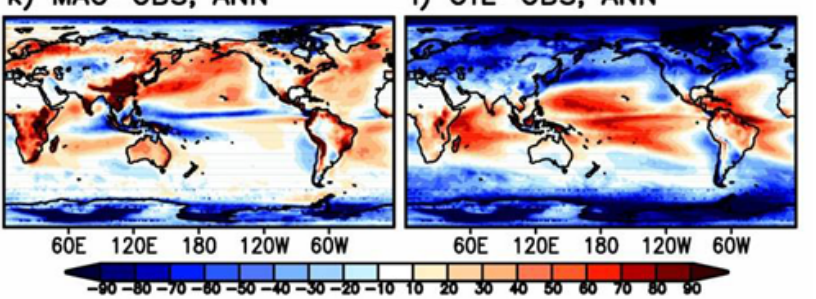

Fig. 5. 10-yr climatology of cloud total water path (TWP) in $\mathrm{g} \mathrm{m}^{-2}$ for DJF (top), JJA (middle), and ANN (bottom) in MAC and CTL runs (left two panels) and MAC minus OBS and CTL minus OBS (right two panels); here MODIS data represent OBS.

large-scale clouds). These ideas can be formulated as algorithms to mitigate the high latitude cloud biases simulated by the McRAS-AC module.

\subsubsection{Total cloud water path}

The geographical distribution of grid-mean total cloud water path (hereafter TWP) equals the sum of cloud liquid water path plus cloud ice water paths; TWP simulated by MAC and CTL runs is compared with MODIS data (Fig. 5). First, CTL biases are consistently negative in the high latitude regions and positive in the tropics. Positive TWP bias in the tropics does not entirely mitigate the negative TWP biases over the high latitudes even though there is much less cloud water there (see Table 3 for means and RMSEs). However, since the effective radii of cloud particles are prescribed in CTL, the cloud mass and number density are decoupled from the cloud water budget. The MAC simulation also exhibits TWP biases of similar magnitudes in the seasonal and annual mean fields, although their geographical distributions are quite different. Too high TWP is due to high water content in the storm tracks along the eastern boundary of Asia and North America following the North Pacific Current and the Gulf Stream. This TWP bias is so strong in the simulated JJA that it significantly biases even the annual averages. Comparatively, the DJF TWP biases are much smaller although the corresponding RMSEs (Table 3) are not. Other contributors to TWP biases are (i) the high latitude regions with strongly negative biases throughout the year in CTL versus annually varying biases in MAC with relatively much smaller annual mean biases; (ii) less than observed TWP in MAC over the ITCZ, and (iii) insufficient stratus clouds and TWP near the west coast of North and South America in both CTL and MAC simulations. Additional cloud physics upgrades are needed to rectify these problems. A plausible cause for large TWP biases in JJA simulation with MAC is identified in one of the sensitivity studies in Sect. 4.2.4

\subsubsection{Liquid/ice cloud water paths}

The simulated grid-mean liquid-cloud water path (hereafter LWP) is shown in Fig. 6. Here, the SSM/I dataset of Weng et al. (1997) that contains data over oceans only, is used as observations. Mean LWP statistics are better for MAC than CTL, whereas for the RMSEs the opposite is true. Evidently, MAC underpredicts LWP in the ITCZ, SPCZ in the DJF, JJA and ANN averages. Once that happens, both mass and number densities of cloud water reduce because precipitation, the primary sink of cloud water, adjusts them similarly. Seethala and Horvath (2010) point out the existence of a systematic low bias in SSM/I LWP caused by partitioning of cloud and precipitating water(s) above $180 \mathrm{~g} \mathrm{~m}^{-2}$ as the microwave algorithm assigns an increasing portion of the liquid water content of thicker non-precipitating clouds to rain water. However, MAC cloud scheme, by design, separates the rainwater from cloud water, whereas CTL cloud scheme assigns it empirically; therefore, this assignment could affect the outcome. We submit that the SSM/I LWP is still a valuable dataset for 
Liquid Water Path $\left[\mathrm{g} / \mathrm{m}^{2}\right]$

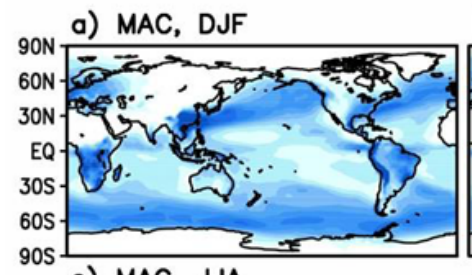

b) CTL, DJF
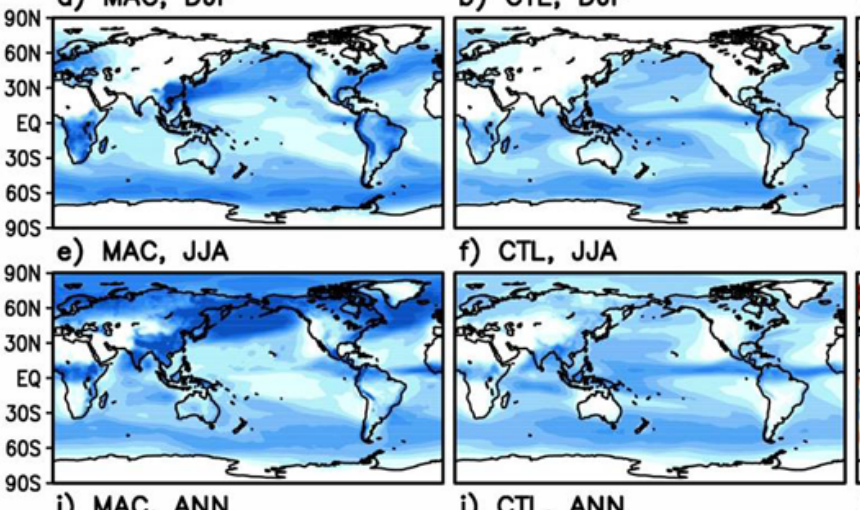

f) CTL, JJA

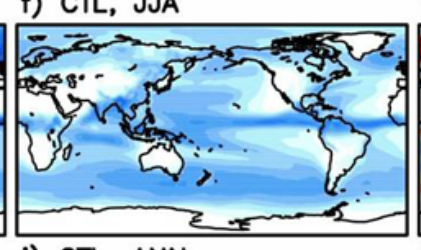

j) CTL, ANN
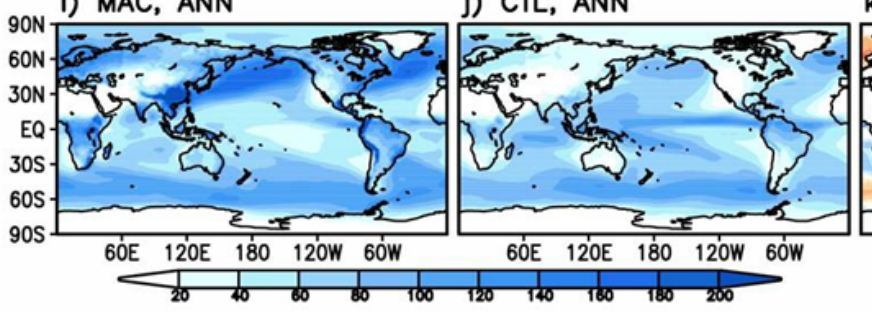

c) MAC-OBS, DJF

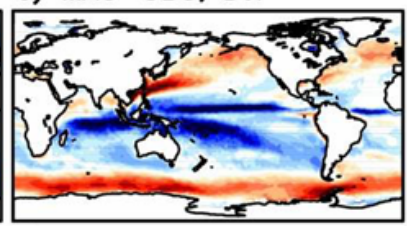

g) $M A C-O B S, J J A$

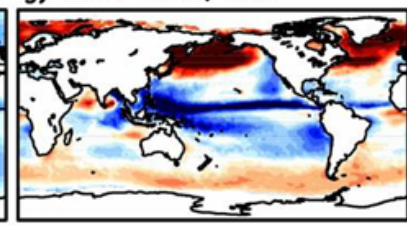

k) MAC-OBS, ANN d) CTL-OBS, DJF

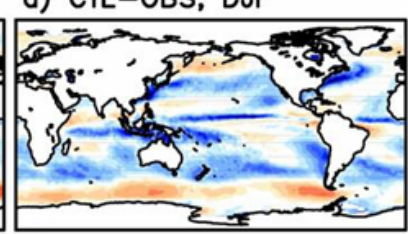

h) $\mathrm{CTL}-O B S, \mathrm{JJA}$

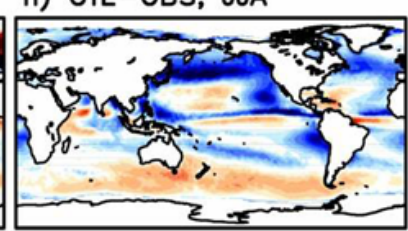

I) CTL-OBS, ANN

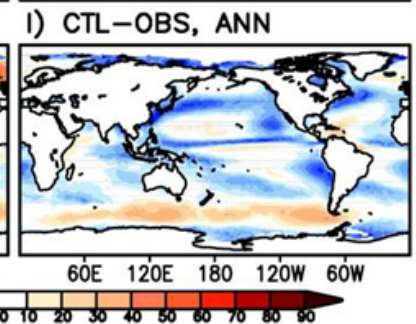

Fig. 6. Same as Fig. 5 except for cloud liquid water path (LWP) in $\mathrm{g} \mathrm{m}^{-2}$; here SSM/I data represent OBS.

evaluation. MODIS, the alternative, retrievals, are unable to infer accurate LWP when the liquid clouds are topped by ice clouds, because the algorithm assumes ice phase for the entire cloud-column.

On other specifics, the positive bias in LWP is similar to that of the TWP in the $40-60^{\circ} \mathrm{S}$ region of roaring winds in DJF. In fact, as the TWP bias reverses in JJA, the LWP still has a small positive bias over the region. One infers that the ice cloud water path, as the difference between TWP and LWP in JJA, becomes too small and that points to lack of IN and a delayed Bergeron process. Indeed, according to the constraints, the Bergeron cloud liquid to ice transfer algorithms must wait until sufficient IN are available for water vapor to deposit. This we believe is related to lack of icenucleating aerosols. Low cloud water path off the west coast of Americas in JJA is to be expected given the lack/absence of boundary layer stratus in both MAC and CTL simulations. The liquid water content in the storm track regions of Asia and east coast of North America (over the nearby ocean) has strong positive (negative) bias for MAC (CTL). The LWP (and TWP; Sect. 4.2.2) biases over the Gulf Stream and North Pacific Current are quite large in the MAC simulation. This is likely related to large-scale clouds and an under prediction of precipitation amount in part due to the high aerosol content of the ambient air mass.

A 1-yr test simulation is made with interactive aerosols generated by the GOCART model instead of the prescribed aerosols from the monthly aerosol climatology of the same model. The interactive run reduces the aerosols in the storm

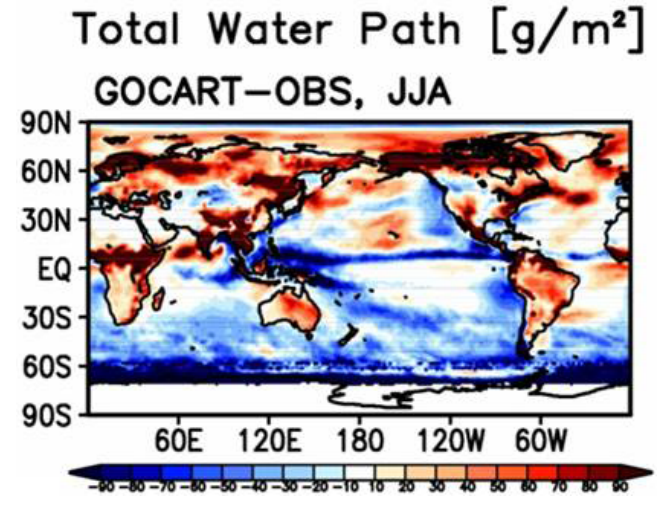

Fig. 7. Cloud TWP for JJA in $\mathrm{g} \mathrm{m}^{-2}$; interactive aerosol chemistry minus observations.

track regions by as much as $70 \%$. More precipitation generated by the rain-storms not only removes the aerosols that have previously acted as $\mathrm{CCN}$ and/or IN, but also wetscavenges the remaining aerosols, a process which is difficult to parameterize given the significant precipitation biases in the GEOS-5 and most other GCMs. Regardless, in the 1-yr test, the high cloud amount and high cloud water path biases of clouds in the storm track regions got remarkably reduced and cloud optical properties became much more realistic suggesting that such biases can be addressed with better aerosol input rather than changes in precipitation microphysics of McRAS-AC (Fig. 7). 


\subsubsection{MODIS simulator inferred cloud water paths}

As stated earlier, MODIS simulator provides in-cloud water, as well as distinguishes between the cloud liquid water path (LWP) and cloud ice-water path (hereafter, IWP) using the same viewing geometry and algorithms for both the satellite inferred and observed cloud fields. The data are derived from a 1-yr test run with MAC and CTL runs. For the sake of brevity, corresponding cloud water path figures are not shown here, but were included in our response to one of the reviewers. The major bias-patterns of cloud water were quite similar to those discussed in Sects. 4.2.2 and 4.2.3, but also containing the interannual variability in the annual cycle in a 1-yr sample; consequently, we have opted to discuss only global means provided in Table 3 . With cloud fraction less than the observed, compensated by in-cloud water path that is roughly twice the observed, the CTL still produces realistic TWP; however, its simulator produces large in-cloud liquid water paths primarily over the oceans (not shown). The corresponding biases in MAC simulator are much smaller. In MAC, in-cloud TWP and LWP show global mean positive (negative) biases (Table 3). However, the grid mean liquid path, defined by in-cloud water path times the cloud fraction, is similar in both CTL and MAC simulations, and this is how the global means of radiation are close to observations in both cloud schemes (Table 3). This suggests compensating biases could artificially yield a more realistic answer; it is therefore imperative to look at both cloud fractions and cloud water paths. Indeed, as pointed out earlier, simulators may also misguide about the source of the cloudiness fraction and cloud optical properties biases, and hence the usefulness of keeping track of GCM simulated cloud fractions in three dimensions along with their optical properties for evaluating the realism of simulated cloud-radiation interaction cannot be over emphasized.

\subsection{Cloud particle effective radii}

Validation satellite data of cloud particle effective radii are based on radiances reflected by the cloud particles. Thus the contribution of a cloud particle to its cloud-column effective radius reduces with increasing cloud depth from the top. Hence the effective radius data get weighted more by the near cloud-top cloud particles. The effective radii of ice and liquid cloud particles produced in MAC and CTL simulations are compared against MODIS satellite data (Platnick et al., 2003). Figure 8 (and Table 3 ) shows that the columnaveraged liquid effective radii $\left(r_{\text {eff }}\right)$ of the MAC simulation are in the range of $10-18 \mu \mathrm{m}$ with a global average value of 14.3 to $14.4 \mu \mathrm{m}$ in DJF and JJA seasons. On global average, the model $r_{\text {eff }}$ is less than the observed by $1-1.5 \mu \mathrm{m}$, whereas the $r_{\text {eff }}$ values provided by MODIS simulator are larger by $1-2 \mu \mathrm{m}$ and agree better with the MODIS data. Both are well within the spread of the observations (not shown). For CTL, the corresponding values of $r_{\text {eff }}$ are in the 9-14 $\mu \mathrm{m}$ range with
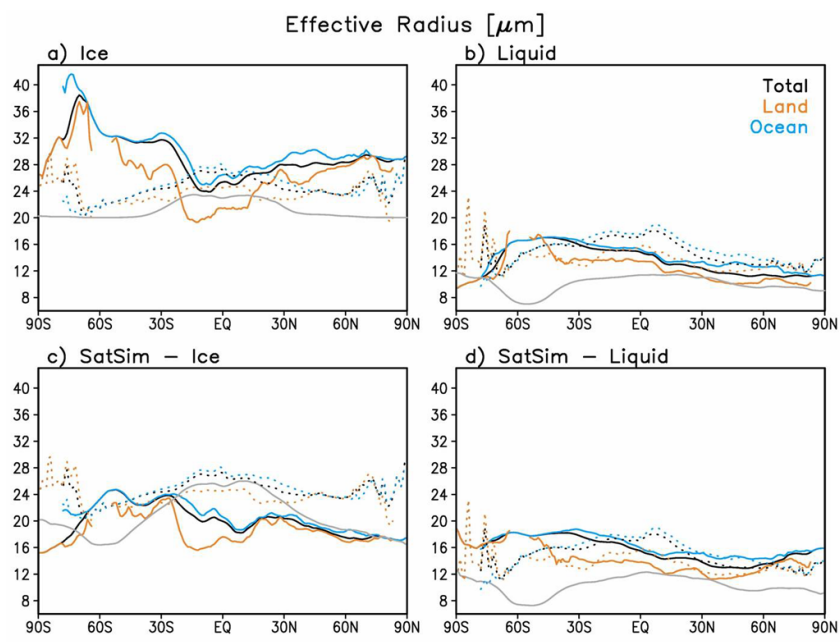

Fig. 8. Zonal average effective radii $(\mu \mathrm{m})$ of (a) ice and (b) liquid cloud particles. Color legends, displayed in the plots, distinguish land, ocean, and all regions. MODIS curves are dotted, MAC curves solid, and CTL curves gray (note: only one curve represents the prescribed values in CTL). (c) and (d) show the corresponding effective radii $(\mu \mathrm{m})$ curves for the $1-y r$ run using the MODIS simulator.

global average values of 10.1 to $10.5 \mu \mathrm{m}$ for DJF and JJA respectively. They are only about $0.5 \mu \mathrm{m}$ larger for the corresponding MODIS simulator. Thus the CTL effective radii are about $30 \%$ smaller than the MODIS data. The liquid particle size in McRAS-AC depends upon aerosol activation, and we argue the input aerosols easily have more than 5-10\% biases, because their numbers are estimates based on aerosol optical depths validated at a few locations and not the entire oceans. The small global mean MAC $r_{\text {eff }}$ bias is quite satisfactory even though some persistent biases are notable in

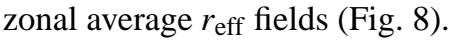

The simulated column-averaged effective radii of ice cloud particles are in $24-42 \mu \mathrm{m}$ range with an average of 28.3 to $29.9 \mu \mathrm{m}$ for JJA and DJF respectively. Clearly MAC simulates larger effective radii, but again it is about $10 \%$ or $3 \mu \mathrm{m}$ too large, which is well within the observational uncertainty. In fact, $3 \mu \mathrm{m}$ in $30 \mu \mathrm{m}$ can be addressed by the uncertainties in the relationship between the effective and volume radius of ice particles. In CTL, the prescribed ice particle effective radius is $\sim 3 \mu \mathrm{m}$ less than observed. However, its zonal biases tell us that polar ice clouds suffer from low concentrations and large sizes of ice particles. The RMSEs for MAC are twice as large, which is not too surprising because MAC (compared to CTL) has more degrees of freedom, which increases the uncertainty and variability. Hence MACsimulated effective radii, being actual predictions, have a large spread as compared to CTL (Fig. 8). Based on these results, MAC-simulated liquid and ice cloud-particle effective radii are quite realistic for GCM applications as long as the CREs also turn out to be satisfactory. 
The effective radii from the MODIS simulator (which show greater sensitivity to near cloud-top particles) in MAC are larger (smaller) for liquid (ice) clouds without reducing the bias (Fig. 8c and d). The global average changes in cloud ice and liquid effective radii are also shown in Table 3. MODIS simulator in MAC reduces the inferred cloud ice particle radius by almost $8-9 \mu \mathrm{m}$, whereas the liquid effective radius increases by about $1-2 \mu \mathrm{m}$. This difference may be due to liquid clouds under ice clouds being misinterpreted as ice clouds. Thus the simulators reveal some consistently inferred bias, whereas the actual effective radii may be better represented through direct fields that have not been transformed by the MODIS simulator; these differences show how much the satellite fields may differ from the real.

The global average liquid (ice) particle numbers simulated by MAC are about $40(3.8) \mathrm{cm}^{-3}$ with corresponding incloud values of $\sim 90(10) \mathrm{cm}^{-3}$. There are no direct measurements to serve as observations of global distribution of cloud particle number climatology, but these are very much dependent on in-cloud aerosol-particle number. Together with the radiation biases at the top of the atmosphere, one can presume that some large regional biases in MAC-simulated CRE (discussed in the next section) may well be aerosol input related.

\subsection{Top-of-atmosphere (TOA) radiation data fields}

\subsubsection{TOA radiation budget}

In this subsection we assess briefly the verisimilitude of the radiation budget produced by the 10 -yr simulations of GEOS-5 with the two cloud schemes. We compare model simulated TOA LW and SW zonal fluxes to their counterparts from CERES (Loeb et al., 2009, CERES dataset EBAF 2.6) in Fig. 9 for DJF, JJA, and ANN fields; corresponding global mean biases and RMS errors are provided in Table 3. Assessments of deficiencies in the simulated cloud fields that lead to discrepancies between the modeled and observed radiation fields are mostly left for the next subsection, which frames the discussion in terms of CREs.

The zonal-average TOA radiation plots, shown in Fig. 9, indicate that, for the most part, MAC matches OBS better than CTL. As will be discussed further later, despite MAC's tropical convective clouds having too little cloud water/ice and somewhat lower height than CTL, the resulting outgoing longwave radiation (OLR) and absorbed shortwave radiation (ASW) are closer to observations than CTL, whose overactive convection yields too much reflected SW and too little OLR. MAC's TOA radiation fields diverge, however, more from observations at midlatitudes with too much ASW in the SH summer (discussed in more detail later) and too much OLR in the NH summer.

MAC and CTL simulations agree with global mean OLR observations to within $2 \mathrm{~W} \mathrm{~m}^{-2}$ (Table 3 ), but MAC's RMSE values are better by $1-2 \mathrm{~W} \mathrm{~m}^{-2}$ for both seasonal and annual

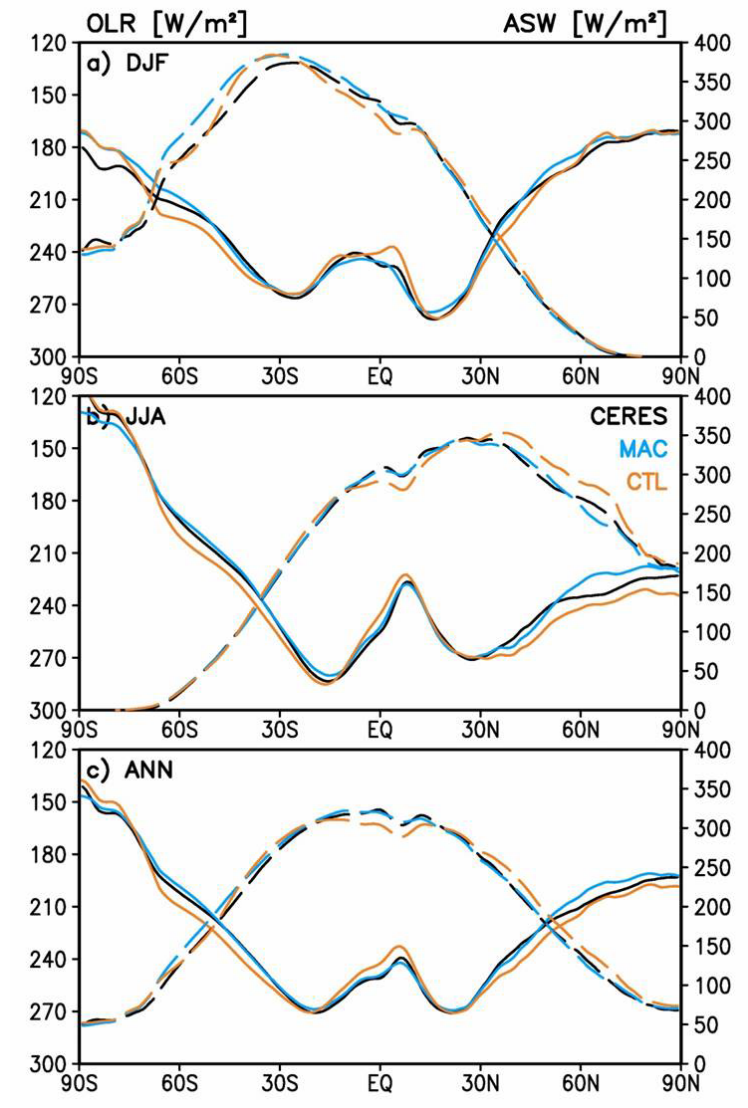

Fig. 9. 10-yr mean zonal average TOA OLR (solid, left axis) and TOA ASW (dashed, right axis) in $\mathrm{W} \mathrm{m}^{-2}$ for DJF (top), JJA (middle), and ANN (bottom) CERES data. MAC and CTL simulations are color coded.

averages, indicating larger spatial error cancellations for CTL. The annual averages of global ASW are about the same for both cloud schemes, and about $2.5 \mathrm{~W} \mathrm{~m}^{-2}$ larger than the observations, consistent with the overall underestimates of total cloud amounts. However, summer and winter global values differ substantially between the two schemes. The ASW of MAC differs by $\sim 17 \mathrm{~W} \mathrm{~m}^{-2}$ between DJF and JJA while the corresponding differences in both observations and CTL are about half. Again, this is a result of biases in the MAC SH midlatitude marine clouds (possible reasons and remedies are discussed later) making the RMSE slightly worse than CTL in DJF (Table 3). The same issue impacts the global net TOA flux, which is $\sim 9 \mathrm{~W} \mathrm{~m}^{-2}$ too high for MAC in DJF compared to CERES. The global net TOA flux for JJA is within $\sim 1 \mathrm{~W} \mathrm{~m}^{-2}$ of observations for both MAC and CTL, but the DJF error of MAC is too large, yielding a substantial excess of $8.5 \mathrm{~W} \mathrm{~m}^{-2}$ in annual global net TOA radiation. Our simulations are not much affected by this large energy imbalance because of externally prescribed SSTs. The RMSEs of net TOA radiation are worse for MAC than CTL for DJF, but are better for JJA and about the same for ANN. 
Nevertheless, taking all radiation quantities into account, and focusing on their RMSEs (which are not affected by spatial cancellations), MAC generally produces radiation fields that are closer to observations than CTL. This is reaffirmed in the next subsection, which examines cloud radiative effects.

\subsubsection{TOA cloud radiative effect}

A well-established way for assessing the influence of clouds on the radiation budget is via the CRE, a quantity also popularly known as cloud radiative forcing (Harrison et al., 1990). CRE for either solar/shortwave (SW) or thermal infrared/longwave (LW) radiation is defined as

$$
\mathrm{CRE}_{\mathrm{LW}, \mathrm{SW}}=F_{\mathrm{LW}, \mathrm{SW}}^{\mathrm{cld}}-F_{\mathrm{LW}, \mathrm{SW}}^{\mathrm{clr}}
$$

which can also be recast as

$$
\mathrm{CRE}_{\mathrm{LW}, \mathrm{SW}}=C_{\mathrm{tot}}\left(F_{\mathrm{LW}, \mathrm{SW}}^{\mathrm{ovc}}-F_{\mathrm{LW}, \mathrm{SW}}^{\mathrm{clr}}\right)
$$

under the assumption that the cloudy sky flux can be written as the linear combination of clear and overcast fluxes. In the above, $F$ is the net downward (i.e., downward minus upward) flux (LW or SW), the superscripts clr designates clear (cloudfree) skies, cld designates all-sky conditions (containing a mixture of cloudy and clear skies), and ovc designates overcast skies ( $100 \%$ cloud fraction); $C_{\text {tot }}$ is the total vertically projected cloud fraction, which in the AGCM depends on individual layer cloud fractions and assumptions about how they overlap. While both definitions can be used for analyzing observational data, the model CRE always comes from Eq. (1a). Nevertheless, Eq. (1b) is preferable for interpreting AGCM CRE. For two different cloud schemes producing the same $C_{\text {tot }}$, the CRE differences mainly arise from their water path/effective radius differences (their combined effect is captured by the cloud optical depth) in the SW, and cloud top height differences in the LW (although optical depth differences also play some role at low values of optical depth) through their effect on $F^{\text {ovc }}$.

The CRE as defined above can be calculated at either TOA or at the surface. Here we only show TOA results for which the observed values are more reliable. In the SW, the CRE TOA is usually negative, because the net (absorbed) flux for cloudy skies is smaller than for clear skies. In the LW, the TOA CRE is usually positive, because the upward TOA flux is greater under clear skies than cloudy skies (the downward flux is zero in both cases). The CRE of net radiation is $\mathrm{CRE}_{\text {net }}=\mathrm{CRE}_{\mathrm{SW}}+\mathrm{CRE}_{\mathrm{LW}}$ and can be positive or negative depending on the specific cloud properties. Measurements of TOA CRE are readily available from CERES, among other sources, and can be used for model evaluation. Here we use EBAF version 2.6 of the CERES dataset (Loeb et al., 2009).

In an earlier paper, Oreopoulos et al. (2012) showed that, for diagnostic radiation calculations with a different radiation scheme, the TOA CRE and its sensitivity to cloud vertical distribution of clouds was quite different for baseline and McRAS-AC clouds. Based on the results of Oreopoulos et

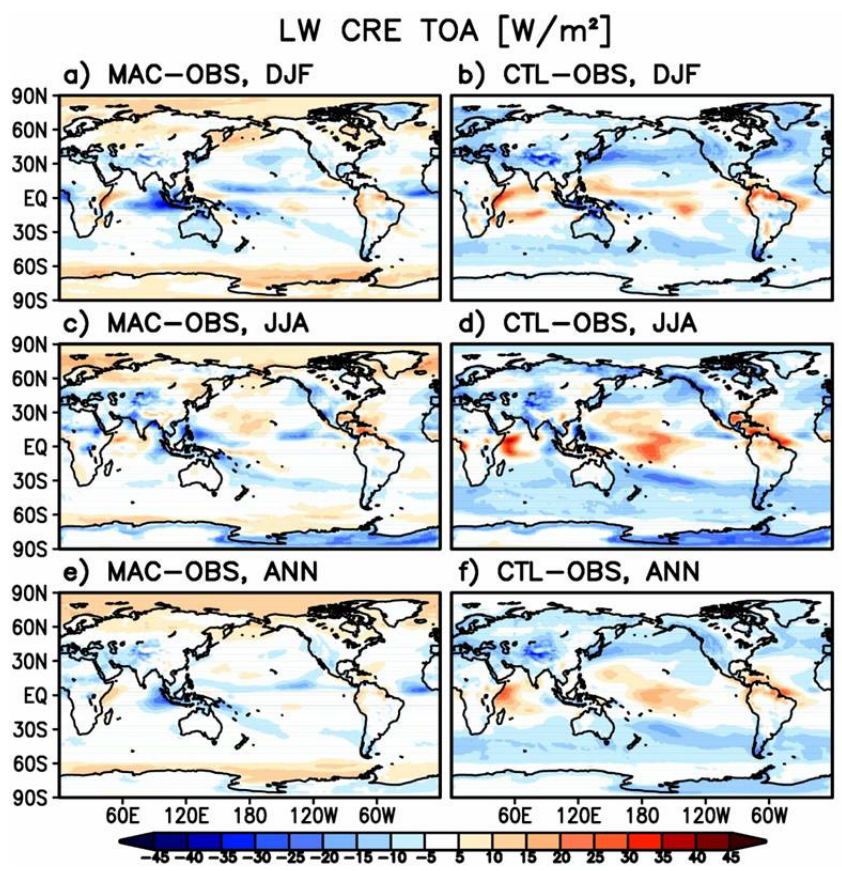

Fig. 10. 10-yr mean maps of simulated LW CRE TOA minus OBS in $\mathrm{W} \mathrm{m}^{-2}$. Plots show DJF (top), JJA (middle) and ANN (bottom). Right (left) columns are for CTL (MAC).

al. (2012), we expect substantial CRE differences between MAC and CTL. The TOA CRE $E_{\mathrm{LW}}$ differences between observations and the two model runs are shown in Fig. 10. The lighter shade of colors for MAC minus OBS compared to CTL minus OBS is indicative of the overall smaller biases for MAC, and this is especially true over the Pacific. The $\mathrm{CRE}_{\mathrm{LW}}$ biases in both simulations are consistent with those of cloud fraction bias discussed earlier in Sect. 4.2.1. In the ITCZ region, MAC exhibits smaller $\mathrm{CRE}_{\mathrm{LW}}$ than observations, probably because its convective clouds are too low or too thin (or both), while CTL exhibits the opposite behavior, i.e., larger than observed $\mathrm{CRE}_{\mathrm{LW}}$, suggesting that convective clouds in CTL may be too high and/or too thick and too spatially extensive. In general, the MAC underestimates are lower than the CTL overestimates. Lower cloud tops in MAC may be due to the influence of the larger quadratic entrainment in McRAS-AC, which reduces the in-cloud moist static energy and keeps clouds shallow versus linear in the standard RAS of the GEOS-5 GCM (Sud and Walker, 2003a). In fact, when we examine all the places with abundance of convective clouds, the simulated $\mathrm{CRE}_{\mathrm{LW}}$ in CTL is consistently too large suggesting that either cloud tops are too high or the cloud free areas are too few or too small. By entraining less air compared to McRAS, RAS generates more condensate per unit detrained mass-flux in the convective anvil; naturally, that would require less mass flux detrainment to eliminate the cloud work function (or CAPE) generated in the physics time step. In other words, both cloud fraction and $\mathrm{CRE}_{\mathrm{LW}}$ would 


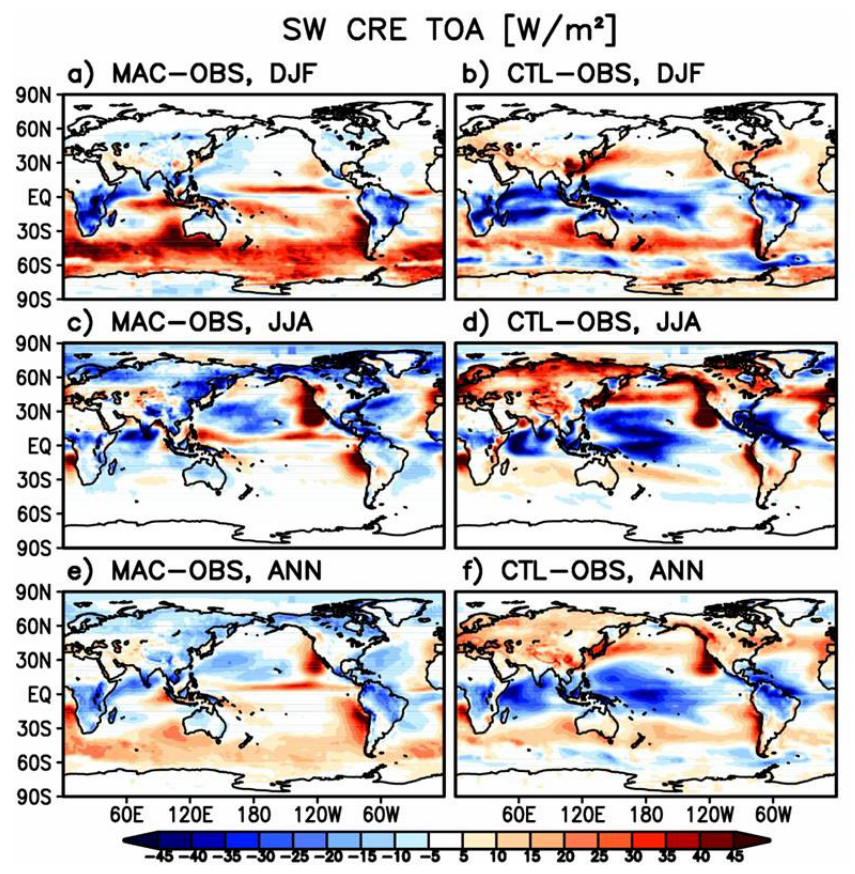

Fig. 11. Same as Fig. 10, but for simulated SW CRE TOA minus OBS in $\mathrm{W} \mathrm{m}^{-2}$.

increase if the entrainment assumption in CTL were made quadratic, and the positive convective $\mathrm{CRE}_{\mathrm{LW}}$ biases would become worse. A plausible reason for cloud height underestimate by MAC is less convective available potential energy (CAPE) due to quadratic entrainment in MAC versus the linear entrainment in CTL.

Despite the previously mentioned weaknesses in the simulation of southern mid-latitude clouds over the ocean by MAC, CRE $E_{L W}$ biases are not as high because most of the clouds are low and do not have much influence on the $\mathrm{CRE}_{\mathrm{LW}}$. On the other hand, in the snow- and ice-covered polar regions (where observed CRE may be less reliable), both the positive and negative biases are generally larger in MAC than in CTL. Overall, the CTL scheme underestimates global CRE $\mathrm{LW}_{\mathrm{L}}$ by $\sim 4 \mathrm{~W} \mathrm{~m}^{-2}$ (Table 3 ) despite the systematic overestimates in convective areas. The MAC simulation approaches the global observed value within $\sim 1.0-1.5 \mathrm{~W} \mathrm{~m}^{-2}$ and achieves better RMSE scores than CTL in both the seasonal and annual means by $\sim 1.5-3 \mathrm{~W} \mathrm{~m}^{-2}$.

Figure 11 shows TOA CRE $\mathrm{SW}_{\mathrm{W}}$ radiation difference maps. $\mathrm{CRE}_{\mathrm{SW}}$ fields of CTL minus OBS have deeper colors with more structure compared to those of MAC minus OBS. Large differences in the biases are evident in MAC and CTL over northern midlatitudes in JJA. But the most prominent MAC biases (underestimates) appear in DJF in the $40^{\circ} \mathrm{S}-60^{\circ} \mathrm{S}$ latitude zone where MAC produces too few ice particles (the annual mean total water path is close to observations, whereas the simulated liquid and ice particle sizes are $20-25 \%$ too large, presumably a consequence of too few IN) that are

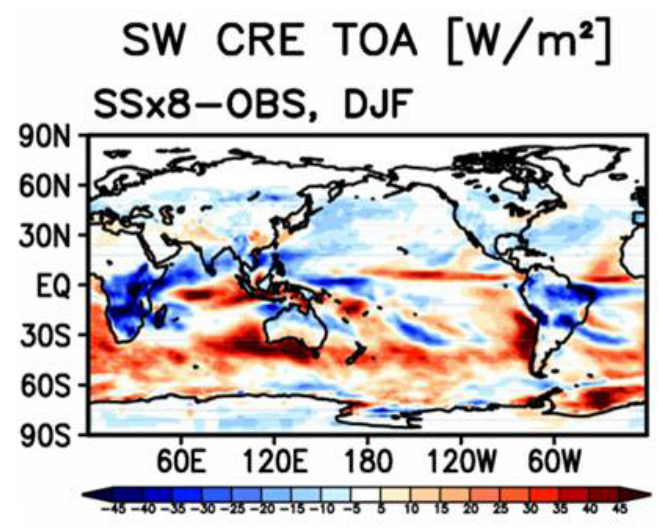

Fig. 12. DJF SW TOA CRE for a 1 -yr MAC simulation using 8 times the sea salt particle numbers.

too big (see Sect. 4.3). Since the region is dominated by sea salt aerosols, we hypothesize that either these aerosols are not activated adequately, or the inferred particle numbers from the GOCART mass concentrations are too low. To examine the impact of the latter possibility, we conducted a 1-yr run where we reduced the sea-salt aerosol diameter by $50 \%$ across the board resulting in an 8-fold increase in aerosol particle number density (APND). This is a reasonable sensitivity test because GOCART simulates mass balances employing only the mass tendency as sum of sources, sinks, aerosol chemistry and advection. APND for different bins is estimated from volume radius and density that match the aerosol optical thickness. The 8-fold increase in the sea salt APND resulted in a TOA CRE $\mathrm{SW}_{\mathrm{S}}$ field very similar to that of CTL (Fig. 12). Whereas this experiment isolated a likely cause of the bias in question, it cannot be considered the sole source of the CPNC underestimates. For example, more ice particle numbers can also be created by a physically based ice-cloud particle multiplication algorithm. The region is predominantly in the rising branch of the Ferrel cell where winds are strong and gusty; consequently CPNC increases due to cloud particle colliding and shattering, ignored in the current version of McRAS-AC, can be significant. Another mechanism that would increase IPNC is liquid cloud particles glaciating sooner (at temperatures larger than $-8^{\circ} \mathrm{C}$ ) as opposed to getting depleted by BergeronFindeisen mass exchange between liquid drops and ice particles through evaporation-deposition process. Reducing the biases with better algorithms would not only mitigate the CPNC biases over $40^{\circ} \mathrm{S}-60^{\circ} \mathrm{S}$, but would also have the potential benefit of improving $\mathrm{CRE}_{\mathrm{SW}}$ biases elsewhere as well. We are actively working on a more physically based solution of this problem.

The similarities of some biases appearing in both simulations suggest either the influence of their common RAS (Moorthi and Suarez, 1992) heritage or other shared model deficiencies such as absence of boundary-layer stratus 
Total CRE TOA $\left[\mathrm{W} / \mathrm{m}^{2}\right]$

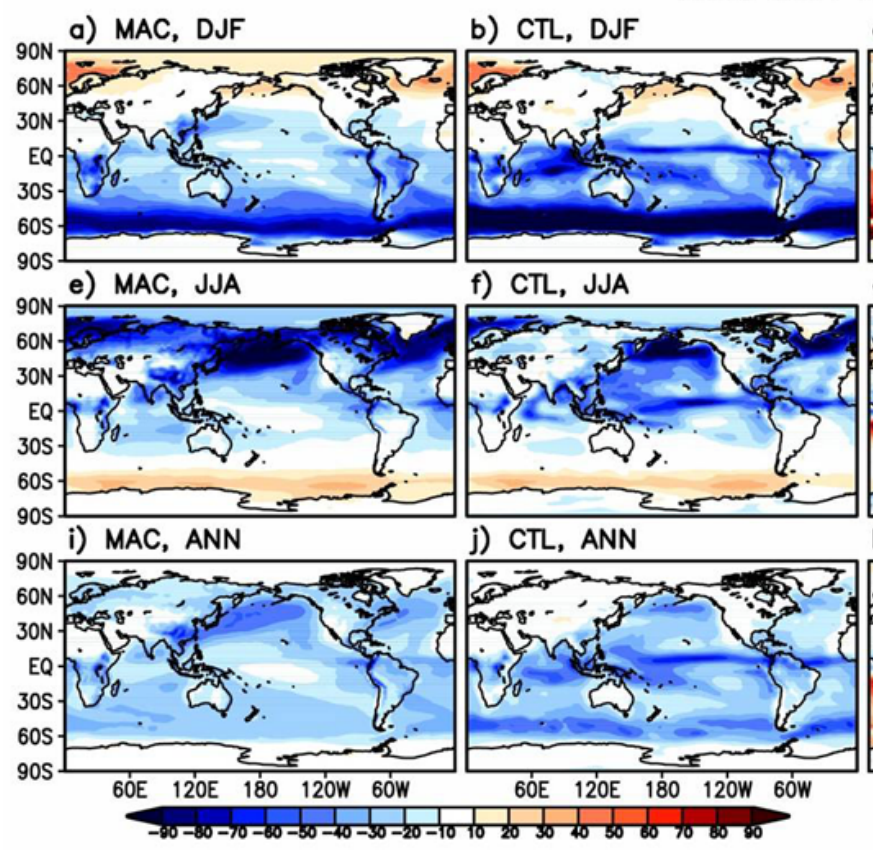

c) MAC-OBS, DJF
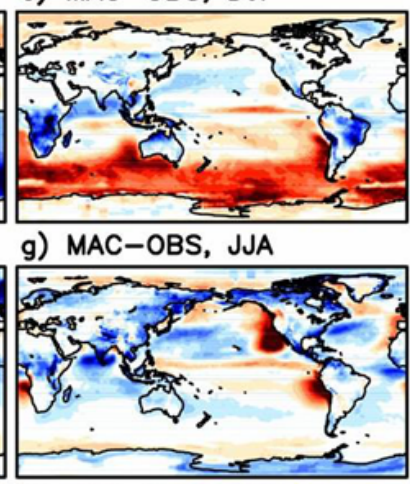

k) MAC-OBS, ANN

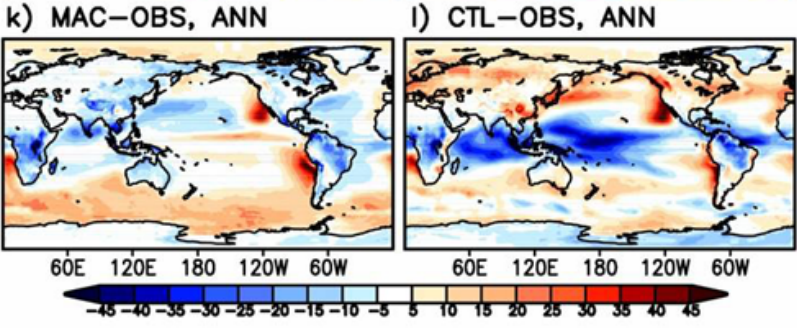

Fig. 13. Simulated 10-yr mean TOA CRE $\mathrm{CH}\left(\mathrm{W} \mathrm{m}^{-2}\right.$ ) for DJF (top), JJA (middle), and ANN (bottom) by MAC and CTL runs (left 2 panels) and MAC minus OBS and CTL minus OBS (right two panels); CERES data represent OBS.

clouds, and excessive orographic precipitation. Wherever the diagnostics show similar biases, a common cause, not related to aerosol-cloud interaction, is possibly the culprit. Regarding the positive biases (underestimates of CRESW) of both simulations over the PBL stratus regions off the west coast of California and Peru, an ad hoc tuning of the PBL vertical moisture transport ameliorated this problem in a test version of GEOS-5 GCM, but a more physically sound alternative is needed, such as the scheme of Bretherton and Park (2009), which has successfully simulated realistic stratus clouds off west coast of North and South America as shown in Kay et al. (2012).

The positive $\mathrm{CRE}_{\mathrm{SW}}$ biases in southern midlatitude oceans between $40^{\circ} \mathrm{S}-60^{\circ} \mathrm{S}$ are big enough to cause a global mean underestimate of $5 \mathrm{~W} \mathrm{~m}^{-2}$ in DJF when the SH insolation peaks. For the same reason, for SH summer, MAC's RMSE is slightly larger than CTL even though for JJA and ANN the RMSE is notably smaller for MAC. The global ANN CRE of MAC is $1 \mathrm{~W} \mathrm{~m}^{-2}$ too low since the $\mathrm{SH}$ summer underestimate is larger than the NH summer overestimate. CTL simulates better the summer $\mathrm{SH}$, but contains in general more bias compensations as evidenced by the larger RMSEs in JJA and ANN.

The bias fields of $\mathrm{CRE}_{\text {net }}$ (Fig. 13) reflect previously discussed issues. In areas where $\mathrm{CRE}_{\mathrm{LW}}$ is small, the $\mathrm{CRE}_{\mathrm{SW}}$ biases take over; see for example the $\mathrm{SH}$ midlatitude oceans (MAC) and PBL stratus areas (both simulations). MAC fares better in the intensely convective regions: apparently its
$\mathrm{CRE}_{\mathrm{SW}}$ and $\mathrm{CRE}_{\mathrm{LW}}$ underestimates largely cancel out, because they have opposite signs. On the other hand, for CTL the tropical overestimates of $\mathrm{CRE}_{\mathrm{SW}}$ are significantly larger than the overestimates of $\mathrm{CRE}_{\mathrm{LW}}$ resulting in too strong (too negative) $C R E_{\text {net }}$, thus implying that the region loses radiative energy at a rate larger than that of CERES observations. Based on the global values of $\mathrm{CRE}_{\text {net }}$ alone (Table 3), one could erroneously conclude that CTL simulates better cloud fields than MAC. But much of the agreement with CERES is fortuitous and a result of cancellations between the SW and LW CRE as well as spatial cancellations. Indeed, MAC's RMSEs of $\mathrm{CRE}_{\text {net }}$ are lower on both the seasonal and annual basis.

\subsection{Comments on the statistics of circulation differences}

One notes at the outset that MAC and CTL simulations are closer to each other than the satellite data as so-called "observations". One would naturally like to find out where McRAS$\mathrm{AC}$ really made a difference vis-à-vis the baseline AGCM and whether it is statistically significant and/or beneficial for the climate forecast. Significant changes in precipitation in convective regions are the only easily explained differences between MAC and CTL and those are discussed in Sect. 4.1.2. We found some differences in the circulation as well, but most of them were local, i.e., without much large-scale structure. Other significant differences were limited to regions where the input data are sparse, while the 4dimensional data assimilation (4DDA) analysis verification 
data reflect the influence of the physics of the baseline model; in such regions, the biases are less for the CTL simulation than MAC. A prime example is 100 to $200 \mathrm{hPa}$ temperature biases in the tropics where 4DDA analysis is a proxy for observations. There is virtually very few data in this region, and the 4DDA fields are largely constrained by the background model performing the data assimilation. For the GMAO (Global Modeling and Assimilation Office) analysis, the background model is the GEOS-5 AGCM with baseline cloud physics. Even though quite straightforward, we have elected to leave such an analysis for the future.

\section{Summary and conclusion}

We examined two 10-yr-long simulations with the GEOS-5 AGCM with prescribed SSTs. One simulation used the baseline model and the other used the McRAS-AC cloud physics as implemented the GEOS-5 GCM, consisting of the McRAS cloud physics developed by Sud and Walker (1999a) with subsequent upgrades (Sud and Walker, 2003a, b), aerosol cloud interaction (using Fountoukis and Nenes, 2005 for CCN activation and Barahona and Nenes, 2009a, b, for ice nucleation, replacing Liu and Penner, 2005) plus Sud and Lee (2007) two moment microphysics for liquid precipitation. Results show the following.

1. The McRAS-AC (MAC) simulation produced comparable circulation and precipitation fields to the baseline GEOS-5 AGCM (CTL) simulation. There are small regions scattered throughout with significant differences in the circulation and precipitation fields, but most of the major circulation features are similar (not shown). Accordingly, it is not trivial to unequivocally characterize one of them as superior. In the global mean and RMSE biases of precipitation, the MAC simulation has a clear edge over the CTL. Nevertheless, large $40^{\circ} \mathrm{S}-60^{\circ} \mathrm{S}$ biases in radiative $\mathrm{CRE}$ and cloud water path over the storm track regions and largely absent low level stratus (where both schemes are similarly deficient) preclude us from declaring MAC superior at this stage. Specifically, low cloud particle numbers over the $40^{\circ} \mathrm{S}-60^{\circ} \mathrm{S}$ regions are certainly related to underestimates of seasalt aerosol-particle numbers as well as absence of cloud particle multiplication by collision and splintering. Ice nucleation also lacks the full range of IN-producing aerosols. These are important issues making ice nucleating processes and aerosols to be an active area of research (e.g., DeMott et al., 2011; Sesartic et al., 2012). Similar problems have been pointed out in other models, and the general consensus is that merely tuning the current algorithms does not solve the problems. The high cloud water path in the storm track region may be related to inefficient/insufficient wet-scavenging of aerosols as demonstrated by the sensitivity test.
2. Overall MAC-simulated cloud optical properties have smaller biases as compared to CTL and that leads to better CRE of both longwave and shortwave radiation as well as net CRE. However, MAC simulates larger $\left(4.7 \mathrm{~W} \mathrm{~m}^{-2}\right)$ absorbed net radiation as compared to $\mathrm{CTL}\left(2.0 \mathrm{~W} \mathrm{~m}^{-2}\right)$ against less than $1 \mathrm{~W} \mathrm{~m}^{-2}$ in the CERES data. At the outset, it suggests a cloud model with better CRE can produce poor TOA net radiation balance; its explanation may be the following. Bias in the net radiation absorbed by the Earth-atmosphere system has contributions from biases in atmospheric humidity, and externally prescribed fields such as surface albedo of the Earth. We need to look at biases in those fields as well.

3. The original McRAS-AC scheme produced better shallow boundary layer clouds in GEOS-4 based on the explicit dry convection developed specifically along the lines of moist convection following Arakawa-Schubert (Arakawa and Schubert, 1974), but it was not implemented in GEOS-5 AGCM in favor of GEOS-5's own PBL physics. This compromise may be responsible for the poor PBL clouds simulated by McRAS-AC at high latitudes and forming low level clouds too close to the surface.

4. The globally averaged MAC-simulated liquid cloud particle effective radius matches the observed remarkably well. On this measure, liquid cloud parameterization of MAC is as good as expected in a GCM. However, there is a limited potential for upgrades to improve the Bergeron-Findeisen liquid to ice transfer. The simulated zonal averages effective radii are also in good agreement with observations, whereas the prescribed effective radii in CTL runs reveal some large systematic biases and very little zonal variability. McRAS-AC simulated cloud particle effective radii for liquid (ice) clouds are somewhat larger (smaller) compared to the MODIS observations, but both are better than the empirical function estimates of the baseline model even though GEOS-5 GCM with prescribed effective radii gives less RMSEs. Cloud ice particle splintering, together with better aerosol datasets, has the potential to ameliorate the cloud ice particle number biases simulated by McRAS-AC.

5. McRAS-AC cloud model with aerosol-cloud-radiation interaction is much more sophisticated as compared to the baseline cloud model of GEOS-5 GCM, and yields better CRE. However, it is unable to produce relatively bias-free cloud liquid and ice paths. Using single column model intercomparison, Morrison et al. (2009) inferred that models generally overestimate both liquid and ice water path, even though there was a large spread among models. The corresponding single-layer, lowlevel mixed-phase stratocumulus simulation, as well as 
previous studies of shallow mixed-phase Arctic clouds, showed an underprediction of liquid water path (Klein et al., 2009). Clearly, the outcomes vary depending upon the region or the scale of the domain being examined. Thus cloud water and ice predictions still have significant bias problems and more work is needed to reduce them. In the end, no matter how sophisticated the parameterization, and how accurate the input data are, biases will still surface in a AGCM; the aim is to reduce the most major biases so that the model is capable of simulating climate that can provide useful guidance about climate issues of interest.

6. Two single year simulations were conducted with the CTL and MAC versions of the simulations using the COSP software providing MODIS-like and ISCCP-like cloud output from AGCM-simulated cloud fields. The results show how simulator versus satellite retrievals are helpful in understanding a model's biases. Satellite simulators provide a very different picture of cloud water path fields and cloud particle effective radii for liquid and ice clouds. Even though model-simulated fields are available at the model's sigma levels, the satellite simulator and satellite observations respond to different parts of the cloud field identically, i.e., using the same assumptions in the retrieval algorithms. The most conspicuous effect of the satellite simulator was classifying cloud liquid beneath cloud ice as all cloud ice reducing the cloud ice effective radius by $30 \%$ and increasing the cloud water effective radius by about $10 \%$ compared to column-average values. The corresponding CTL simulation with prescribed particle sizes shows much smaller effect of the MODIS simulator. Evidently, if one uses satellite data for model validation, the satellite simulator is a better discriminator of model biases, because the correspondence between satellite simulators and model output fields cannot be generalized.

7. Recognizing that aerosol cloud radiation interaction parameterization is still in its infancy, and the cloud models show discernible biases in aerosol cloud interactions (e.g., Kay et al., 2012), we submit that the McRAS-AC cloud scheme is able to perform at least as well as the baseline cloud scheme of the GEOS-5 GCM despite a few regional biases in the cloud optical properties (that are potentially correctable), and therefore McRAS-AC model shows promise for future. Given that McRASAC contains state-of-the art aerosol-cloud interactions that are fully coupled across the scales, a version of GEOS-5 AGCM that includes the scheme will be a valuable tool for climate research.

We reiterate biased CRE are the primary cause of biases in the circulation and precipitation climatology that potentially interact with the climate change anomalies one expects to simulate with a climate model. Sometimes the climate change problem has smaller radiative forcing anomalies than the model's intrinsic biases. For example, a doubling of $\mathrm{CO}_{2}$ produces a mere $3-5 \mathrm{~W} \mathrm{~m}^{-2}$ radiative forcing, while models simulating its influences often have biases as large as $30 \mathrm{~W} \mathrm{~m}^{-2}$ in some regions. Realizing that even the relative positions of the biases vary among the models, good regional-scale consensus among the climate models is unlikely. Increasing the size of the domain under examination helps, because the CRE biases often reduce via spatially varying bias cancellations. When the region becomes sufficiently large, the radiative forcing anomalies can exceed the model's biases and thereby show a more robust signal and better possibility of consensus. A prime example is better consensus among models in global mean changes in climate change scenarios. Nevertheless, if the aim of climate research is regional-scale predictions, we must eliminate, as much as possible, the climate model's CRE biases. On this premise, we venture to profess that lower CRE biases are a fundamental measure of the usefulness of a climate model, even though, in principal, better CRE can also result from incorrect combinations of cloud fraction, cloud water paths, and effective cloud particle sizes, but not everywhere. Thus, for predicting changes in the regional annual cycle of precipitation and circulation climatology and its steady reduction, this warrants further research.

Acknowledgements. The authors thank David Considine, Manager of the Modeling and Analysis Program of the Earth Science Division at NASA Headquarters for supporting this research. Computational resources were provided by a separate proposal to the NASA Centre for Climate Simulation (NCCS). Thanks are also due to both anonymous reviewers of GMD and our topical editor, Klaus Gierens, who helped with many worthy recommendations to improve the paper

Edited by: K. Gierens

\section{References}

Abdul-Razzak, H. and Ghan, S. J.: A Parameterization of Aerosol Activation. Part 2: Multiple Aerosol Types, J. Geophys. Res., 105, 6837-6844, doi:10.1029/1999JD901161, 2000.

Abdul-Razzak H. and Ghan, S. J.: A Parameterization of Aerosol Activation. Part 3: Sectional Representation, J. Geophys. Res., 107, 4026, doi:10.1029/2001JD000483, 2002.

Adler, R. F., Huffman, G. J., Chang, A., Ferraro, R., Xie, P., Janowiak, J., Rudolf, B., Schneider, U., Curtis, S., Bolvin, D., Gruber, A., Susskind, J., Arkin, P., and Nelkin, E.: The version-2 global precipitation climatology project (GPCP) monthly precipitation analysis (1979-Present), J. Hydrometeor., 4, 1147-1167, 2003.

Albrecht, B. A.: Aerosols, Cloud Microphysics, and Fractional Cloudiness, Science, 245, 1227-1230, 1989.

Andreae, M. O. and Rosenfeld, D.: Aerosol-cloud-precipitation interactions. Part 1. The nature and sources of cloud-active aerosols, Earth-Sci. Revi., 89, 13-41, 2008. 
Arakawa, A. and Schubert, W. H.: Interaction of cumulus cloud ensemble with the large-scale environment, Part I, J. Atmos. Sci., 31, 674-701, 1974.

Bacmeister, J. T., Suarez, M. J., and Robertson, F.: Rain reevaporation, Boundary layer convection interaction and Pacific rainfall patterns in an AGCM, J. Atmos. Sci., 63, 3383-3403, doi:10.1175/JAS3791.1, 2006.

Bangert, M., Kottmeier, C., Vogel, B., and Vogel, H.: Regional scale effects of the aerosol cloud interaction simulated with an online coupled comprehensive chemistry model, Atmos. Chem. Phys., 11, 4411-4423, doi:10.5194/acp-11-4411-2011, 2011.

Barahona, D. and Nenes, A.: Parameterizing the competition between homogeneous and heterogeneous freezing in ice cloud formation - polydisperse ice nuclei, Atmos. Chem. Phys., 9, 59335948, doi:10.5194/acp-9-5933-2009a, 2009a.

Barahona, D. and Nenes, A.: Parameterizing the competition between homogeneous and heterogeneous freezing in cirrus cloud formation - monodisperse ice nuclei, Atmos. Chem. Phys., 9, 369-381, doi:10.5194/acp-9-369-2009, 2009b.

Barahona, D., West, R. E. L., Stier, P., Romakkaniemi, S., Kokkola, H., and Nenes, A.: Comprehensively accounting for the effect of giant $\mathrm{CCN}$ in cloud activation parameterizations, Atmos. Chem. Phys., 10, 2467-2473, doi:10.5194/acp-10-2467-2010, 2010.

Benedetti, A., Reid, J. S., and Colarco, P. J.: International Cooperative for Aerosol Prediction Workshop on aerosol forecast verification, B. Am. Meteorol. Soc., 92, ES48-ES53, doi:10.1175/BAMS-D-11-00105.1, 2011.

Bergeron, T.: On the physics of cloud and precipitation, Proc. 5th Assembly U.G.G.I. Lisbon, 2, 156-178, 1935.

Bell, T. L., Yoo, J.-M., and Lee, M.-I.: Note on the weekly cycle of storm heights over the southeast United States, J. Geophys. Res., 114, D15201, doi:10.1029/2009JD012041, 2009a.

Bell, T. L., Rosenfeld, D., and Kim, K.-M.: The weekly cycle of lightning: evidence of storm invigoration by pollution, Geophys. Res. Lett., 36, L23805, doi:10.1029/2009GL040915, 2009b.

Bellouin, N., Rae, J., Jones, A., Johnson, C., Haywood, J., and Boucher, O.: Aerosol forcing in the Climate Model Intercomparison Project (CMIP5) simulations by HadGEM2-ES and the role of ammonium nitrate, J. Geophys. Res., 116, D20206, doi:10.1029/2011JD016074, 2011.

Bretherton, C. S. and Park, S.: A new moist turbulence parameterization in the Community Atmosphere Model, J. Climate, 22, 3422-3448, 2009.

Chao, W.: Correction of Excessive Precipitation over Steep and High Mountains in a GCM, J. Atmos. Sci., 69, 1547-1561, doi 10.1175/JAS-D-11-0216.1, 2012.

Chen, Y. and Del Genio, A. D.: Evaluation of tropical cloud regimes in observations and a general circulation model, Clim. Dynam., 32, 355-369, doi:10.1007/s00382-008-0386-6, 2009.

Chin, M., Ginoux, P., Kinne, S., Holben, B. N., Duncan, B. N., Martin, R. V., Logan, J. A., Higurashi, A., and Nakajima, T.: Tropospheric aerosol optical thickness from the GOCART model and comparisons with satellite and sunphotometer measurements, J. Atmos. Sci. 59, 461-483, 2002.

Chou, M.-D. and Suarez M. J.: A solar radiation parameterization for atmospheric studies, Technical Report Series on Global Modeling and Data Assimilation, NASA/TM-1999-10460, 15, 52 pp., 1999.
Chou, M.-D., Suarez, M. J., Liang, X.-Z., and Yan, M. M.-H.: A Thermal Infrared Radiation Parameterization for Atmospheric Studies, Technical Report Series on Global Modeling and Data Assimilation, NASA/TM-2001-104606, 19, 65 pp., 2001.

Colarco, P., da Silva, A., Chin, M., and Diehl, T.: Online simulations of global aerosol distributions in the NASA GEOS-4 model and comparisons to satellite and ground-based aerosol optical depth, J. Geophys. Res., 115, D14207, doi:10.1029/2009JD012820, 2010.

Cotton, W. R. and Pielke, R. A.: Human impact on weather and Climate, Cambridge University Press, 288 pp., 1995.

Del Genio, A. D., Yao, M. S., Kovari, W. K., and Lo, K. W.: A prognostic cloud water parameterization for global climate models, J. Climate, 9, 270-304, 1996.

DeMott, P. J., Möhler, O., Stetzer, O., Vali, G., Levin, Z., Petters, M. D., Murakami, M. ,Leisner, Th., Bundke, U., Klein, H., Kanji, Z. A., Cotton, R., Jones, H., Benz, S., Brinkmann, M., Rzesanke, D., Saathoff, H., Nicolet, M., Saito, A., Nillius, B., Bingemer, H., Abbatt, J. P. D., Ardon, K., Ganor, E., Georgakopoulos, D. G., Saunders, C.: Resurgence in ice nuclei measurement research, B. Am. Meteorol. Soc., 92, 1623-1635, doi:10.1175/2011BAMS3119.1, 2011.

Fountoukis, C. and Nenes, A.: Continued development of a cloud droplet formation parameterization for global climate models, J. Geophys. Res., 110, D11212, doi:10.1029/2004JD005591, 2005.

Ghan, S. J., Randall, D., Xu, K. M., Cederwall, R., Cripe, D., Hack, J., Iacobellis, S., Klein, S., Krueger, S., Lohmann, U., Pedretti, J., Robock, A., Rotstayn, L., Somerville, R., Stenchikov, G., Sud, Y. C., Walker, G. K., Xie, S., Yio, J., and Zhang, M.: A comparison of single column model simulations of summertime midlatitude continental convection, J. Geophys. Res. Atmos., 105, 2091-2124, 2000.

Ghan, S. J., Abdul-Razzak, H., Nenes, A., Ming, Y., Liu, X., Ovchinnikov, M, Shipway, B., Meskhidze, N., Xu, J., and Shi, X.: Droplet Nucleation: Physically-Based Parameterization and Comparative Evaluation, J. Adv. Model. Earth Syst., 3, M10001, doi:10.1029/2011MS000074, 2011.

Gibbs, J. W.: On the Equilibrium of Heterogeneous Substances, Part 1, Transactions of the Connecticut Academy of Arts and Sciences III, 108-248, 1876.

Gibbs, J. W.: On the Equilibrium of Heterogeneous Substances, Part 2, Transactions of the Connecticut Academy of Arts and Sciences III, 343-524, 1878.

Greenler, R.: Rainbows, Halos, and Glories, Milwaukee: Peanut Butter Publishing, 195 pp., 1999.

Gunturu, U. B.: Aerosol-Cloud Interactions: A New Perspective in Precipitation Enhancement Ph.D. Thesis, Department of Earth, Atmospheric and Planetary Sciences, MIT, 186 pp., 2010.

Harrison, E. F., Minnis, P., Barkstrom, B. R., Ramanathan, V., Cess, R. D., and Gibson, G. G.: Seasonal variation of cloud radiative forcing derived from the Earth Radiation Budget Experiment, J. Geophys. Res., 95, 18687-18703, 1990.

IPCC, Climate Change: The Physical Science Basis. Contribution of Working Group I to the Fourth Assessment Report of the Intergovernmental Panel on Climate Change, edited by: Solomon, S., Qin, D., Manning, M., Chen, Z., Marquis, M., Averyt, K. B., Tignor, M., and Miller, H. L., Cambridge University Press, Cambridge, United Kingdom and New York, NY, USA, 2007. 
Johnson, R. H., Rickenbach, T. M., Rutledge, S. A., Ciesielski, P. E., and Schubert, W. H.: Trimodal Characteristics of Tropical Convection, J. Climate, 12, 2397-2418, doi:10.1175/15200442(1999)012<2397:TCOTC>2.0.CO;2, 1999.

Kay, J. E., Hillman, B. R., Klein, S. A., Zhang, Y., Medeiros, B., Pincus, R., Gettelman, A., Eaton, B., Boyle, J., Marchand, R., and Ackerman, T. P.: Exposing globalcloud biases in the Community Atmosphere Model (CAM) usingsatellite observations and their corresponding instrument simu-lators, J. Climate, 25, 5190-5207, doi:10.1175/JCLI-D-11-00469.1, 2012.

Khvorostyanov, V. I. and Curry, J. A.: The Theory of Ice Nucleation by Heterogeneous Freezing of Deliquescent Mixed CCN. Part II: Parcel Model Simulation, J. Atmos. Sci., 62, 261-285, doi:10.1175/JAS-3367.1, 2005.

Kim, K. M., Lau, K. M., Sud, Y. C, and Walker, G. K.: Influence of aerosol radiative forcings on the diurnal and seasonal cycles of rainfall over West Africa and Eastern Atlantic Ocean using GCM simulations, Clim. Dynam, 35, 115-126, doi:10.1007/s00382010-0750-1, 2010.

Kim, M.-K., Lau, K. -M., Chin, M., Kim, K.-M., Sud, Y. C., and Walker, G. K.: Atmospheric teleconnection over Eurasia induced by aerosol radiative forcing during boreal spring, J. Clim., 19, 4700-4718, 2006.

Klein, S. A., McCoy, R. B., Morrison, H., Ackerman, A. S., Avramov, A., Boer, G. De, Chen, M., Cole, J. N. S., DelGenio, A. D., Falk, M., Foster, M., Fridlind, A., Golaz, J.-C., Hashino, T., Harrington, J. Y., Hoose, C., Khairoutdinov, M. F., Larson, V. E., Liu, X., Luo, Y., McFarquhar, G. M., Menon, S., Neggers, R. A. J., Park, S., Poellot, M. R., Schmidt, J. M., Sednev, I., Shipway, B. J., Shupe, M. D., Spangenberg, D., Sud, Y. C. Turner, D. D., Veron, D., von Salzen, E. K., Walker, G. K., Wang, Z., Wolf, A. B., Xie, S., Xu, K.-M., Yang, F., and Zhang, G.: Intercomparison of model simulations of mixed-phase clouds observed during the ARM Mixed-Phase Arctic Cloud Experiment. Part I: Single layer cloud, Q. J. Roy. Meteorol. Soc., 135, 979-1002, doi:10.1002/qj.416, 2009.

Köhler, H.: The nucleus in and the growth of hygroscopic droplets, Trans. Faraday Soc., 32, 1152-1161, doi:10.1039/TF9363201152, 1936.

Koren, I., Altaratz, O., Remer, L. A., Feingold, G., Martins, J. V., and Heiblum, R. H.: Aerosol-induced intensification of rain from the tropics to the mid-latitudes, Nat. Geosci., 5, 118-122, doi:10.1038/ngeo1364, 2012.

Koster, R. D., Suarez, M. J., Ducharne, A., Stieglitz, M., and Kumar, P.: A catchment-based approach to modeling land surface processes in a GCM, Part 1, Model Structure, J. Geophys. Res., 105, 24809-24822, doi:10.1029/2000JD900327, 2000.

Krishnamurti, T. N., Chakraborty, A., Martin, A., Lau, W. K., Kim, K.-M., Sud, Y. C., and Walker, G. K.: Impact of Arabian Sea Pollution on the Bay of Bengal Winter Monsoon Rains, J. Geophys. Res., Atmos., 114, D06213, doi:10.1029/2008JD010679, 2009.

Kulkarni, G. and Dobbie, S.: Ice nucleation properties of mineral dust particles: determination of onset RHi, IN active fraction, nucleation time-lag, and the effect of active sites on contact angles, Atmos. Chem. Phys., 10, 95-105, doi:10.5194/acp-10-95-2010, 2010.

Lance, S., Shupe, M. D., Feingold, G., Brock, C. A., Cozic, J., Holloway, J. S., Moore, R. H., Nenes, A., Schwarz, J. P., Spackman, J. R., Froyd, K. D., Murphy, D. M., Brioude, J., Cooper,
O. R., Stohl, A., and Burkhart, J. F.: Cloud condensation nuclei as a modulator of ice processes in Arctic mixed-phase clouds, Atmos. Chem. Phys., 11, 8003-8015, doi:10.5194/acp-11-80032011, 2011.

Lau, K. M. and Kim, K. M.: Does aerosol strengthen or weaken the Asian Monsoon?, in: Mountains: Witnesses of Global Change, edited by: Baudo, R., Tartari, G., and Vuillermoz, E., Elsevier, 340 pp., 2007.

Lau, K. M., Kim, K. M., Sud, Y. C., and Walker, G. K.: A GCM study of the response of the atmospheric water cycle of West Africa and the Atlantic to Saharan dust radiative forcing, Ann. Geophys., 27, 4023-4037, doi:10.5194/angeo-27-40232009, 2009.

Li, Z.-Q., Niu, F., Fan, J., Liu, Y. G., Rosenfeld, D., and Ding, Y.: Long-term impacts of aerosols on the vertical development of clouds and precipitation, Nat. Geosci., 4, 888-894, doi:10.1038/ngeo1313, 2011.

Liu, X. and Penner, J. E.: Ice nucleation for global models, Meteorol. Z., 14, 499-514, 2005.

Liu, X., Xie, S., Boyle, J., Klein, S. A., Shi, X., Wang, Z., Lin, W., Ghan, S. J., Earle, M., Liu, P., and Zelenyuk, A.: Testing Cloud Microphysics Parameterizations in NCAR CAM5 with ISDAC and M-PACE Observations, J. Geophys. Res., 116, D00T11, doi:10.1029/2011JD015889, 2011.

Loeb, N. G., Wielicki, B. A., Doelling, D. R., Smith, G. L., Keyes, D. F., Kato, S., Manalo-Smith, N., and Wong, T.: Toward Optimal Closure of the Earth's Top-of-Atmosphere Radiation Budget, J. Climate, 22, 748-766, doi:10.1175/2008JCLI2637.1, 2009.

Lohmann, U.: Aerosol effects on clouds and climate, Space Sci. Rev., 125, 129-137, 2006.

Maloney, E. D. Hartmann, D. L.: The Sensitivity of Intraseasonal Variability in the NCAR CCM3 to Changes in Convective Parameterization., J. Climate, 14, 2015-2034, doi.org/10.1175/1520-0442, 2001.

Molod, A., Takacs, L., Suarez, M. J., Bacmeister, J., Song, I.-S., and Eichmann, A.: GEOS-5 Atmospheric General Circulation Model: mean climate development from MERRA to Fortuna, Tech. Memo., NASA Goddard Space Flight Center, MD, 115 pp., 2012.

Moorthi, S. and Suarez, M. J.: Relaxed Arakawa-Schubert - a Parameterization of Moist Convection for General-Circulation Models, Mon. Weather Rev., 120, 978-1002, 1992.

Morrison, H. and Gettelman, A.: A new two-moment bulk stratiform cloud microphysics scheme in the NCAR Community Atmosphere Model (CAM3), Part I: Description and numerical tests, J. Climate, 21, 3642-3659, 2008.

Morrison, H., McCoy, Klein, S. A., Avramov, A., Chen, M., Cole, J. N. S., DelGenio, A. D., Falk, M., Foster, M., Fridlind, A., Golaz, J.-C., Hashino, T., Harrington, J. Y., Hoose, C., Khairoutdinov, M. F., Larson, V. E., Liu, X., Luo, Y., McFarquhar, G. M., Menon, S., Neggers, R. A. J., Park, S., Poellot, M. R., Schmidt, J. M., Sednev, I., Shipway, B. J., Shupe, M. D., Spangenberg, D., Sud, Y.C., Turner, D. D., Veron, D., Walker, G. K., Wang, Z., Wolf, A. B., Xie, S., Xu, K.-M., Yang, F., and Zhang, G.: Intercomparison of model simulations of mixed-phase clouds observed during the ARM Mixed-Phase Arctic Cloud Experiment. II: Multilayer cloud, Q. J. Roy. Meteorol. Soc., 135, 1003-1019, doi:10.1002/qj.415, 2009. 
Nenes, A. and Seinfeld, J. H.: Parameterization of cloud droplet formation in global climate models, J. Geophys. Res., 108, 4415, doi:10.1029/2002JD002911, 2003.

Nenes, A., Ghan, S. J., Abdul-Razzak, H., Chuang, P., and Seinfeld, J.: Kinetic Limitations on Droplet Formation, Tellus Series B, Chem. Phys. Meteorol., 53, 133-149, 2001.

Oreopoulos, L., Lee, D., Sud, Y. C., and Suarez, M. J.: Radiative impacts of cloud heterogeneity and overlap in an atmospheric General Circulation Model, Atmos. Chem. Phys., 12, 9097-9111, doi:10.5194/acp-12-9097-2012, 2012.

Platnick, S., King, M. D., Ackerman, S. A., Menzel, W. P., Baum, B. A., Riedi, J. C., and Frey, R. A.: The MODIS cloud products: algorithms and examples from Terra, Trans. Geosci. Remote Sens., 41, 459-473, 2003.

Quaas, J., Boucher, O., and Bréon, F.-M.: Aerosol indirect effects in POLDER satellite data and the Laboratoire de Météorologie Dynamique-Zoom (LMDZ) general circulation model, J. Geophys. Res., 109, D08205, doi:10.1029/2003JD004317, 2004.

Randall, D. A.: The Evolution of Complexity in General Circulation Models, in: The Development of Atmospheric General Circulation Models: Complexity, Synthesis, and Computation,, edited by: Donner, L., Schubert, W., and J. Somerville, R. C., Cambridge University Press, 272 pp., 2010.

Reinecker, M. M., Suarez, M. J., Todling R., Bacmeister J., Takacs L., Liu H.-C., Gu, W., Sienkiewicz M., Koster, R. D., Gelaro, R., Stajner, I., and Nielsen, J. E.: The GEOS-5 Data Assimilation System Documentation of Versions 1 5.0.1, 5.1.0, and 5.2.0. NASA/TM-2008-2 104606, 27, 118 pp., 2008.

Reynolds, R. W., Rayner, N. A., Smith, T. M., Stokes, D. C., and Wang, W.: An improved in situ and satellite SST analysis for climate, J. Climate, 15, 1609-1625, 2002.

Roelofs, G. J., Stier, P., Feichter, J., Vignati, E., and Wilson, J.: Aerosol activation and cloud processing in the global aerosolclimate model ECHAM5-HAM, Atmos. Chem. Phys., 6, 23892399, doi:10.5194/acp-6-2389-2006, 2006.

Rosenfeld, D.: Suppression of rain and snow by urban and industrial air pollution, Science, 287, 1793-1796, 2000.

Rosenfeld, D.: Aerosol-cloud interactions control of earth radiation and latent heat release budgets, Space Sci. Rev., 125, 149-157, doi:10.1007/s11214-006-9053-6, 2006.

Rosenfeld, D. and Bell, T.: Why do tornados and hail storms rest on weekends? J. Geophys. Res. Atmos., 116, D20211, doi:10.1029/2011JD016214, 2011.

Rossow, W. B. and Schiffer, R. A.: Advances in understanding clouds from ISCCP, B. Am. Meteorol. Soc., 80, 2261-2288, doi:10.1175/1520-0477(1999)080<2261:AIUCFI > 2.0.CO;2, 1999.

Rotstayn, L. D., Ryan, B., and Katzfey, J.: A scheme for calculation of the liquid fraction in mixed-phase stratiform clouds in largescale models, Mon. Weather Rev., 128, 1070-1088, 2000.

Seethala, C. and Horváth, A.: Global assessment of AMSR$\mathrm{E}$ and MODIS cloud liquid water path retrievals in warm oceanic clouds, J. Geophys. Res., 115, D13202, doi:10.1029/2009JD012662, 2010.

Seifert, A. and Beheng, K. D.: A double-moment parameterization for simulating autoconversion, accretion and self collection, Atmos. Res., 59, 265-281, 2001.

Seifert, A. and Beheng, K. D.: A two-moment cloud microphysics parameterization for mixed-phase clouds, Part 1: Model descrip- tion, Meteorol. Atmos. Phys., 92, 45-66, 2006.

Seinfeld, J. H. and Pandis, S. N.: Atmospheric Chemistry and Physics - From Air Pollution to Climate Change, 2nd Edn., John Wiley \& Sons., 987 pp., 2006.

Sesartic, A., Lohmann, U., and Storelvmo, T.: Bacteria in the ECHAM5-HAM global climate model, Atmos. Chem. Phys., 12, 8645-8661, doi:10.5194/acp-12-8645-2012, 2012.

Smith, R. N. B.: A scheme for predicting layer-clouds and their water content in a General circulation model, Q. J. Roy. Meterol. Soc., Part B, 116, 435-460, 1990.

Stevens, B. and Feingold, G.: Untangling aerosol effects on clouds and precipitation in a buffered system, Nature, 461, 607-613, doi:10.1038/nature08281, 2009.

Stull, R. B.: An Introduction to Boundary Layer Meteorology, Kluwer Academic, 666 pp., 1988.

Stubenrauch, C. J., Rossow, W. B., Kinne, S., Ackerman, S., Cesana, G., Chepfer, H., Di Girolamo, L., Getzewich, B., Guignard, A., Heidinger, A., Maddux, B. C., Menzel, W. P., Minnis, P., Pearl, C., Platnick, S., Poulsen, C., Riedi, J., Sun-Mack, S., Walther, A., Winker, D., Zeng, S., and Zhao, G.: ASSESSMENT OF GLOBAL CLOUD DATASETS FROM SATELLITES: Project and Database initiated by the GEWEX Radiation Panel, B. Am. Meteorol. Soc., accepted, 2012.

Sud, Y. C. and Lee, D.: Parameterization of aerosol indirect effect to complement McRAS cloud scheme and its evaluation with the 3year ARM-SGP analyzed data for single column models, Atmos. Res., 2, doi:105-12510.1016/j.atmosres.2007.03.007, 2007.

Sud, Y. C. and Molod, A.: The roles of dry convection, cloudradiation feedback processes and the influence of recent improvements in the parameterization of convection in the GLA GCM, Mon. Weather Rev., 116, 2366-2387, 1988.

Sud, Y. C. and Walker, G. K.: A rain evaporation and downdraft parameterization to complement a cumulus updraft scheme and its evaluation using GATE data, Mon. Weather Rev., 121, 30193039, 1993.

Sud, Y. C. and Walker, G. K.: Microphysics of clouds with the relaxed Arakawa-Schubert Cumulus Scheme (McRAS), Part I: Design and evaluation with GATE Phase III data, J. Atmos. Sci., 18, 3196-3220, 1999a.

Sud, Y. C. and Walker, G. K.: Microphysics of clouds with the relaxed Arakawa-Schubert Cumulus Scheme (McRAS), Part II: Implementation and performance in GEOS II GCM, J. Atmos. Sci., 18, 3221-3240, 1999b.

Sud, Y. C. and Walker, G. K.: New upgrades to the microphysics and thermodynamics of clouds in McRAS: SCM and GCM evaluation of simulation biases in GEOS GCM, Proc. Indian Nat. Sci. Aca., Phys. Sci., 5, 543-565, 2003a.

Sud, Y. C. and Walker, G. K.: Influence of ice-phase physics of hydrometeors on moist-convection, Geophys. Res. Lett., 30, 1758, doi:10.1029/2003GL017587, 2003b.

Sud, Y. C., Wilcox, E., Lau, W. K.-M., Walker, G. K., Liu, X.H., Nenes, A., Lee, D., Kim, K.-M., Zhou, Y., and Bhattacharjee, P. S.: Sensitivity of boreal-summer circulation and precipitation to atmospheric aerosols in selected regions - Part 1: Africa and India, Ann. Geophys., 27, 3989-4007, doi:10.5194/angeo27-3989-2009, 2009.

Sundqvist, H.: Parameterization of condensation and associated clouds in models for weather prediction and general circulation simulation, Physically-Based Modelling and Simulation of 
Climate and Climatic Change, edited by: Schlesinger, M. E., Kluwer Academic Publishers, Dordrecht, the Netherlands, 433461, 1988.

Tiedtke, M.: Representation of Clouds in Large-Scale Models, Mon. Weather. Rev., 121, 3040-3061, 1993.

Twomey, S.: The influence of pollution on the shortwave albedo of clouds, J. Atmos. Sci., 34, 1149-1152, 1977.

Weng, F., Grody, N. C., Ferraro, R. R., Basist, A., and Forsyth, D.: Cloud liquid water climatology from the Special Sensor Microwave Imager, J. Climate, 10, 1086-1096, 1997.

Wilber, A. C., Smith, G. L., Gupta, S. K., and Stackhouse, P. W.: Annual cycles of surface shortwave radiative fluxes, J. Climate, 19, 535-547, 2006.

Wilcox, E. M., Sud, Y. C., and Walker, G.: Sensitivity of borealsummer circulation and precipitation to atmospheric aerosols in selected regions - Part 2: The Americas, Ann. Geophys., 27, 4009-4021, doi:10.5194/angeo-27-4009-2009, 2009.

Xie, S., Xu, K.-M., Cederwall, R. T., Bechtold, P., DelGenio, A. D., Klein, S. A., Cripe, D. G., Ghan, S. J., Gregory, D., Iacobellis, S. F., Krueger, S. K., Lohmann, U., Petch, J. C., Randall, D. A., Rotstayn, L. D., Somerville, R. C. J., Sud, Y. C. VonSalzen, K., Walker, G. K., Wolf, A., Yio, A., Zhang, G. J., and Zhang, M.: Intercomparison and evaluation of cumulus parameterizations under summertime midlatitude continental conditions, Q. J. Roy. Meteorol. Soc., 582, 1095-1136, 2002.
Xu, K.-M., Zhang, M., Eitzen, Z. A., Ghan, S. J., Klein, S. A., Wu, X., Xie, S., Mranson, M., Del Genio, A. D., Iacobellis, S. F., Khairoutdinov, M., Lin, W., Löhmann, Ü., Randall, D. A., Somerville, R. C. J., Sud, Y. C., Walker, G. K., Wolf, A., Yio, J. J., and Zhang, J.: Modeling springtime shallow frontal clouds with cloud-resolving and single-column models, J. Geophys. Res., 110, D15S04, doi:10.1029/2004JD005153, 2005.

Zhang, Z. and Platnick, S.: An assessment of differences between cloud effective particle radius retrievals for marine water clouds from three MODIS spectral bands, J. Geophys. Res., 116, D20215, doi:10.1029/2011JD016216, 2011.

Zhang, Z., Ackerman, A. S., Feingold, G., Platnick, S., Pincus, R., and Xue, H.: Effects of cloud horizontal inhomogeneity and drizzle on remote sensing of cloud droplet effective radius: Case studies based on large-eddy simulations, J. Geophys. Res., 117, D19208, doi:10.1029/2012JD017655, 2012. 